\title{
Unified Granular-number-based AHP-VIKOR multi-criteria decision framework
}

\author{
Kajal Chatterjee $^{1} \cdot$ Samarjit Kar $^{1}$
}

Received: 20 July 2016 / Accepted: 22 January 2017 / Published online: 12 April 2017

(C) Springer International Publishing Switzerland 2017

\begin{abstract}
In most of the real-life problems, data and information in a decision-making process are usually imprecise because of the experts' subjective judgments. The main problem arises when experts, who have different degrees of knowledge about multiple conflicting criteria and alternatives, deal with uncertain data in diverse forms. There are two aims of this paper, the first of which is to define granulation of linguistic information in heterogeneous (fuzzy, rough, interval, or crisp) contexts for group decision-making problems, and thereby its transformation in a homogenous perspective using unified granular number. Second, based on the above, we construct a flexible multi-criteria decision-making (MCDM) framework integrating the Analytic Hierarchy Process and the VIKOR compromise-ranking method in a granular domain, so that we can evaluate the weights of different criteria and hence prioritize alternatives. This methodology can applied in prioritizing risk responses to manage green supply chain risks from the perspective of a plastic manufacturing company. The robustness of our model is monitored by conducting a sensitivity analysis on alternative ranking. In addition, to establish the stability and validity of the ranking result, a comparative analysis of ranking by the proposed method is done with other existing MCDM methods in uncertain domains, namely, through the use of crisp, grey, and rough sets.
\end{abstract}

Samarjit Kar

dr.samarjitkar@gmail.com

Kajal Chatterjee

kajalchatterjee19@yahoo.in

1 Department of Mathematics, National Institute of Technology, Durgapur 713209, India
Keywords Granular number · AHP · VIKOR · Multicriteria decision making (MCDM) · Green supply chain (GSC)

\section{Introduction}

The process of selecting alternatives in an MCDM problem assumes that the psychology and behaviour of the decision makers (DM) will be completely rational (Fan et al. 2013). However, in reality, experts with different backgrounds and levels (granules) of knowledge use linguistic terms to represent their evaluation and also their preferences while solving qualitative group decision-making problems (Xu and Wang 2016). In general, data and information found in the judgment of the experts are subjective as well as inherently non-numeric, and this gives rise to uncertainty and impreciseness with non-probabilistic characteristics (Martinez et al. 2007).

For mitigating these imprecision, fuzzy set-based decision-making algorithms are developed (Chen and Chang 2016). However, in reality, the boundary and membership functions of fuzzy sets are difficult to determine due to their dependency on quantitative information (Zhu et al. 2015a). Considering this deficiency of fuzzy sets, the concept of interval numbers is introduced in the context of decision-making problems. Formation of interval numbers requires only a minimum amount of information. Nevertheless, both fuzzy sets and interval numbers need auxiliary information, such as a predetermined membership function and the interval boundary, with rough sets addressing only a part of them. Rough numbers, having lower and upper limits with rough boundary intervals, depend only on original data avoiding any auxiliary information (Guo and Zhang 2008). Hence, rough numbers 
have a better chance at capturing the real perception and objectivity of the experts (Zhu et al. 2015b). Multi-criteria decision-making (MCDM) methods have been widely applied to support decision makers in selecting the best among multiple alternatives, given various different types of applicable criteria. For example, transformation techniques and operators are defined in the case of the use of a fuzzy set in multi-criteria group decision-making problems (Chen and Tsai 2016; Chen et al. 2016).

The above-mentioned approaches measure uncertain situations, utilizing the decision maker's knowledge and experience that represent cognitions of homogenous information (Martinez et al. 2007). In real life, the decision matrices are filled with information from various domains, and due to their inability to deal adequately with heterogeneous data, existing MCDM methods are often applied to data of the same type (Peng et al. 2013). In this scenario, granular computing, a structured problem-solving method, can be used in those decisionmaking problems, so that experts can express their decisions more flexibly in accordance with their domain knowledge, while at the same time keeping an eye on the problem at hand. Fuzzy sets, rough sets, grey sets, and intervals all fall under the category of Inexact Granular Computing (Pedrycz 2005). Recently, many useful decision-making methods have been developed to deal with multiple attribute decision making within the context of granular computing (Pedrycz and Song 2011; Cabrerizo et al. 2013, 2014; Xu and Wang 2016).

The simple homogeneous pairwise comparison, in an MCDM framework using an individual decision-making approach, is unable to capture the true perception of a decision maker with proper effect and precision. To handle this heterogeneous and inexact group of numbers in the preference representation domain, studies are conducted to create the necessary transformation for each uncertain granular number (Alsawy and Hefny 2013b). Experts tend to assign their preferences in the form of intervals, fuzzy numbers, rough numbers, or any other type of uncertain numbers within the preference relation matrix in the same decision-making problem. Consequently, (Alsawy and Hefny 2013b) developed a new version of Analytic Hierarchy Process (AHP) to deal with such types of uncertain numbers in their specifications. Many researchers have since discussed different versions of AHP with uncertain comparisons individually, viz. crisp AHP (Saaty 1980), AHP with fuzzy ratios in TFN (Van Laarhoven and Pedrycz 1983), AHP with TrFN (Buckley 1985), AHP with extent analysis approach in TFN (Chang 1996), granular AHP (G-AHP) (Alsawy and Hefny 2013b), rough AHP (Zhu et al. 2015b) and D-AHP (Deng et al. 2014), intuitionistic Fuzzy AHP (Xu 2014), Hesitant AHP (Zhu et al. 2016), and generalized analytic network process (Zhu et al. 2015a).
Putting the decision maker's behaviour into light, classical VIKOR also solves decision-making problems in which the weights assigned to a particular criterion are expressed in crisp mode; nonetheless, this approach fails to handle the situation when their values are in multiple formats (Opricovic and Tzeng 2004). Recently, some researchers have extended the VIKOR method to process information in various uncertain environments. For example, Crisp VIKOR (Opricovic and Tzeng 2007), Interval VIKOR (Sayadi et al. 2009), Trapezoidal fuzzy number VIKOR (Shemshadi et al. 2011), Intuitionistic fuzzy VIKOR (Chatterjee et al. 2013b), Hesitant fuzzy VIKOR (Liao and Xu 2013; Liao et al. 2015), Triangular fuzzy number VIKOR (Rostamzadeh et al. 2015), fuzzy Rasch-VIKOR (Chatterjee and Kar 2013a), D-VIKOR (Han and Chen 2014), rough AHPVIKOR (Zhu et al. 2015a), and Type-2 fuzzy VIKOR (Qin et al. 2015). So far, little attention has been paid to VIKOR dealing with heterogeneous granular information. Owing to the complexity and uncertainty that characterize real-life problems, the granular-number-based VIKOR (G-VIKOR) is proposed, which is able to handle heterogeneous data and various forms of criteria weights taken separately.

In this paper, our objective is as follows:

- To develop a new method based on granular computing to solve group decision-making (GDM) problems, where linguistic information is given in heterogeneous contexts. In particular, we focus on group decision-making (GDM) situations defined in multi-granular contexts, that is, situations, where the experts have different backgrounds and levels of knowledge in the problem domain and where degrees of importance are provided or associated with these situations to reflect their importance in solving the problem.

The major contributions of this paper are as follows:

- We propose a flexible hierarchical granular-based AHPVIKOR MCDM methodology that works well with multiple formats (real values, interval values, and linguistic labels) allowing the decision makers to assess freely and according to their preferences.

- These multiple formats used to weigh different criteria are first expressed in unified granular numbers (UGNs) or simply G-numbers and then calculated in keeping with the operations defined on them.

- The main advantage of this approach is to tackle the uncertainty in the performances of both the criteria and the alternatives, putting to use the diverse knowledge of the expert without any loss of information.

- In addition, the method has an ability to represent and manipulate all types of uncertain numbers in a uniform manner, thereby simplifying the arithmetic operations. 
The above methodology is applied in the selection and the prioritization of risk response in a plastic manufacturing company's green supply chain, and we have included a sensitivity analysis for checking the robustness of the proposed method.

To do that, the rest of the paper is organized as follows: Sect. 2 outlines the preliminary concepts involved in granular computing, granular number, and its relevance to decision making, along with the arithmetic operations applicable to granular numbers. Section 3 deals with uncertain numbers and their transformation to granular numbers and vice versa. Comparison of granular numbers is discussed in Sect. 4. Section 5 deals with a proposed Granulation function for managing multi-granular linguistic information. Algorithmic procedures along with brief overviews of a granular-number-based AHP (G-AHP) approach and an extended granular-number-based VIKOR (G-VIKOR) are detailed in Sects. 6 and 7, respectively. Section 8 deals with the application of our proposed methodology in the selection and ranking of green supply chain (GSC) risk criteria along with its risk responses. Results are discussed in Sect. 9, along with a conclusion and future direction drawn in Sect. 10.

\section{Granular number (G-number) and its operations}

\subsection{Granular computing (GrC)}

In a decision-making framework, linguistic information can be made operational by expressing it in terms of information granules that are designed, processed, and interpreted using Granular Computing (GrC) (Cabrerizo et al. 2013). It is an emerging field of study on human-centered knowledge-intensive problem solving using multiple levels of granularity (Yao 2004).

A few important facts on $\mathrm{GrC}$ are as follows:

- Granules are composed of objects combined together by indiscernibility relationships. These granules act as the 'pillars of granular computing' (Pedrycz and Chen 2015b).

- Granular computing processes entities that encapsulate complex information in the form of information granules, which in their turn are formed by the process of the abstraction of data and the derivation of knowledge from available information (Pedrycz and Song 2011; Bargiela and Pedrycz 2003).

- Classical decision-making approaches have traditionally considered the use of an exact and precise algorithm that manipulates only confident data, while GrC processes basic chunks of similar information granules originating at a numeric level (Pedrycz and Gomide 2007).

- In general, the $\mathrm{GrC}$ process can be divided into two subprocesses: granulation and computation. While the former transforms the information available in the problem domain into granules, the latter processes these granules to solve the problem (Pedrycz and Chen 2011, 2015a).

In practice, when a group of experts settles down to solve a particular problem, these experts are seen to have come from different research areas (representing their experiential backgrounds) and different levels of knowledge (representing granules). Granularity may come from uncertainties of different sources (experts and criteria) (Xu and Wang 2016). Granular computing can be advocated for a formal framework, such as interval analysis, rough sets, and probabilistic environment besides fuzzy sets for processing information granules (Pedrycz 2005).

\subsection{Granular number (G-number)}

\subsubsection{Background}

Granulation of information is inherent in human thinking and reasoning processes. When problem involves incomplete, uncertain, and vague information, it may be difficult to detect distinct objects, and one may find it convenient to consider granules for tackling the problem under consideration (Skowron et al. 2016). Unified Granular Number (UGN) or simply Granular Number or G-number is an extension of an ordinary (single-valued) number in such a way that it does not refer to one single value any more, but a connected set of possible values (Alsawy and Hefny 2013b).

- G-Numbers not only representing a higher level of abstraction that holds the common properties of all uncertain granular numbers (although some details are not worth considering) but also offer the benefit of representing all types of inexact granular numbers using the same form (Alsawy and Hefny 2013c).

- In $\mathrm{GrC}$, computations are performed on granules of different structures, where the granularity of information plays an important role (Dubois and Prade 2016).

- According to Alsawy and Hefny (2013a), a G-number can represent all types of multi-granular numbers (rough numbers, vague numbers, grey numbers, and interval numbers) due to its ability to convert them into a homogenous representation, as expressed in Eq. (1). This process of representation also makes the calculations on these numbers easy to perform: 
$X=G\left(c_{X}, r_{X}\right)$,

where $c_{X}$ is the center value and $r_{X}$ is the radius of G-number $X$, respectively (Alsawy and Hefny 2013a). Equation (1) of G-numbers as mentioned above guarantees representing the most common properties of uncertainty having both lower and upper bounds and known boundaries.

- A modification is made to Eq. (1) by considering the area $A(X)$ of granule $X$, which subtends between the number graphs and the $x$-axis to represent the weight of the granular number (Alsawy and Hefny 2013b). Since $A(X)$ represent the covered space (area) or the weight of number $X$ on its domain, a new and improved version of Eq. (1) is presented in this paper through Eq. (2):

$$
X=G \frac{\left(c_{X}, r_{X}\right)}{A(X)} ; \quad 0 \leq|A(X)| \leq 2\left|r_{X}\right|
$$

- This formulation represents the most common properties of different types of uncertainties in a G-number, with both the lower and upper boundaries being present.

\subsubsection{Relevance of G-number in group decision making}

While communicating with one another using a natural language, human beings use words (linguistic terms) instead of numerical values to exchange information. However, while linguistic information is readily available, it is not operational in the sense that we cannot process it in the form of information granules (Pedrycz and Song 2011). In group decision-making (GDM) problems, one attempts to resolve differences of opinions (judgment) expressed by multiple experts. Uncertainty is a pivotal concept in granular computing and related aspects. In fact, one of the main goals of information granules is to express the uncertainty of aggregated data in a synthetic and yet effective way (Livi and Sadeghian 2016).

- The admitted level of granularity in decision matrix gives rise to a granular matrix of pairwise comparison and granular entries by heterogeneous information granules (for most suitable numeric representative) giving required flexibility to experts. This is the main advantage of Granular number.

- The main disadvantage of using G-number is the checking procedure. In comparison for weight criteria prioritization, we have to evaluate the expected value of information granules expressed in multiple formats, and check for its consistency and experts have to change their opinions for the inconsistency of the decision matrix. While prioritization of G-num- bers $X_{i}(i=1,2, \ldots, n)$, we have to follow the rule, given in Eq. (9) (of Sect. 4), along with checking the range of weight $A\left(X_{i}\right)$ that should always lie in range $0 \leq|A(X)| \leq 2\left|r_{X}\right|$.

Briefly, the proposed group decision-making (GDM) method, based on G-number, classified into three steps.

- In the first step, multiple experts will provide their preferences using information granules expressed in heterogeneous context, using a proper granulation function.

- In the second step, multi-granular information is converted to homogeneous G-number using transformation functions and aggregate into a collective piece of information.

- In the third step, using granular-based AHP-VIKOR MCDM methodology, weights of criteria are evaluated along with prioritizing the proposed alternatives.

\subsection{Operations on Granular numbers}

For any two arbitrary G-numbers $X=G \frac{\left(c_{X}, r_{X}\right)}{A(X)}$ and $Y=G \frac{\left(c_{Y}, r_{Y}\right)}{A(Y)}$, the arithmetic operations are defined in the following (Alsawy and Hefny 2013a; Mohamad and Rofai 2015). The validity of the operations is checked here for interval number $[a, b], b>a$. Similarly, the operations are valid for other G-numbers:

1. Addition $\quad$ operation $\quad$ on $\quad$ G-numbers
$X=G \frac{\left(c_{X}, r_{X}\right)}{A(X)}$ and $Y=G \frac{\left(c_{Y}, r_{Y}\right)}{A(Y)}$

$$
X+Y=G \frac{\left(c_{X+Y}, r_{X+Y}\right)}{A(X+Y)}=G \frac{\left(c_{X}+c_{Y}, r_{X}+r_{Y}\right)}{A(X)+A(Y)} .
$$

Example 1 In case of interval numbers

$$
\begin{aligned}
& X=[a, b]=G \frac{\left(c_{X}, r_{X}\right)}{A(X)} ; \quad c_{X}=\frac{a+b}{2}, \quad r_{X}=\frac{b-a}{2}, A(X)=b-a \\
& Y=[c, d]=G \frac{\left(c_{Y}, r_{Y}\right)}{A(Y)} ; \quad c_{Y}=\frac{c+d}{2}, \quad r_{Y}=\frac{d-c}{2}, A(Y)=d-c \\
& X+Y=[a, b]+[c, d]=[a+c, b+d]=G \frac{\left(c_{X+Y}, r_{X+Y}\right)}{A(X+Y)}, \text { where } \\
& c_{X+Y}=\frac{1}{2}(a+c+b+d)=\frac{1}{2}(a+b)+\frac{1}{2}(c+d)=c_{X}+c_{Y} \\
& r_{X+Y}=\frac{1}{2}((b+d)-(a-c))=\frac{1}{2}(b-a)+\frac{1}{2}(d-c)=r_{X}+r_{Y} \\
& A(X+Y)=(b+d)-(a-c)=(b-a)+(d-c)=A(X)+A(Y) .
\end{aligned}
$$


2. Multiplication operation on G-numbers $X=G \frac{\left(c_{X}, r_{X}\right)}{A(X)}$ and $Y=G \frac{\left(c_{Y}, r_{Y}\right)}{A(Y)}$

$X . Y=G \frac{\left(c_{X} c_{Y}+r_{X} r_{Y}, c_{X} r_{Y}+c_{Y} r_{X}\right)}{c_{X} A(Y)+c_{Y} A(X)}$.

Example

$X . Y=[a, b] .[c, d]=[a c, b d]=G \frac{\left(c_{X Y}, r_{X Y}\right)}{A(X Y)}$, where

$$
\begin{aligned}
c_{X Y}=\frac{1}{2}(a c+b d) & =\left[\frac{1}{4}(a c+a d+b c+b d)+\frac{1}{4}(b d-b c-a d+a c)\right] \\
& =\left[\frac{1}{2}(a+b) \cdot \frac{1}{2}(c+d)+\frac{1}{2}(b-a) \cdot(d-c)\right] \\
& =c_{X} \cdot c_{Y}+r_{X} \cdot r_{Y}
\end{aligned}
$$

$r_{X Y}=\frac{1}{2}(b d-a c)=\left[\frac{1}{4}(b d+a d-b c-a c)+\frac{1}{4}(b d+b c-a d-a c)\right]$

$$
\begin{aligned}
& =\left[\frac{1}{2}(a+b) \cdot \frac{1}{2}(d-c)+\frac{1}{2}(c+d) \cdot \frac{1}{2}(b-a)\right] \\
& =c_{X} \cdot r_{Y}+c_{Y} \cdot r_{X}
\end{aligned}
$$

$$
\begin{aligned}
A_{X Y}=(b d-a c) & =\left[\frac{1}{2}(b d-b c+a d-a c)+\frac{1}{2}(b c-a c+b d-a d)\right] \\
& =\left[\frac{1}{2}(a+b) .(d-c)+\frac{1}{2}(c+d) .(b-a)\right] \\
& =c_{X} \cdot A(Y)+c_{Y} \cdot A(X)
\end{aligned}
$$

3. Negation of G-number $X=G \frac{\left(c_{X}, r_{X}\right)}{A(X)}$

$$
-X=G \frac{\left(-c_{X}, r_{X}\right)}{A(X)}
$$

Example
Let $X=[a, b]$, then $-X=[-b,-a]=G \frac{\left(c_{-X}, r_{-X}\right)}{A(-X)}$

$$
c_{-X}=\frac{(-a-b)}{2}=\frac{-(a+b)}{2}=-c_{X}
$$

$r_{-X}=\frac{(-a-(-b))}{2}=\frac{(b-a)}{2}=r_{X}$

$A(-X))=(-a-(-b))=(b-a)=A(X)$.

4. Reciprocal of G-number $G_{X}=G \frac{\left(c_{X}, r_{X}\right)}{A(X)}$

$$
\frac{1}{X}=G \frac{\left(\frac{c_{X}}{c_{X}^{2}-r_{X}^{2}}, \frac{r_{X}}{c_{X}^{2}-r_{X}^{2}}\right)}{\frac{A(X)}{c_{X}^{2}-r_{X}^{2}}} .
$$

\section{Example}

Let $-X=[-b,-a]$ then $\frac{1}{X}=\left[\frac{1}{b}, \frac{1}{a}\right]=G \frac{\left(c_{\frac{1}{X}}, r_{\frac{1}{X}}\right)}{A\left(\frac{1}{X}\right)}$

$$
c_{\frac{1}{\bar{X}}}=\frac{\left(\frac{1}{a}+\frac{1}{b}\right)}{2}=\frac{(a+b)}{2 a b}=\frac{\frac{(a+b)}{2}}{\left(\frac{a+b}{2}\right)^{2}-\left(\frac{b-a}{2}\right)^{2}}=\frac{c_{X}}{\left(c_{X}\right)^{2}-\left(r_{X}\right)^{2}}
$$$$
r_{\frac{1}{X}}=\frac{\left(\frac{1}{a}-\frac{1}{b}\right)}{2}=\frac{(b-a)}{2 a b}=\frac{\frac{(b-a)}{2}}{\left(\frac{a+b}{2}\right)^{2}-\left(\frac{b-a}{2}\right)^{2}}=\frac{r_{X}}{\left(c_{X}\right)^{2}-\left(r_{X}\right)^{2}}
$$

$$
A\left(\frac{1}{X}\right)=\left(\frac{1}{a}-\frac{1}{b}\right)=\frac{(b-a)}{a b}=\frac{(b-a)}{\left(\frac{a+b}{2}\right)^{2}-\left(\frac{b-a}{2}\right)^{2}}=\frac{A(X)}{\left(c_{X}\right)^{2}-\left(r_{X}\right)^{2}} .
$$

5. Subtraction operation on G-numbers

$$
X=G \frac{\left(c_{X}, r_{X}\right)}{A(X)} \text { and } Y=G \frac{\left(c_{Y}, r_{Y}\right)}{A(Y)}
$$

$X-Y=X+(-Y)=G \frac{\left(c_{X}-c_{Y}, r_{X}+r_{Y}\right)}{A(Y)+A(Y)}$.

\section{Example 1 (Contd.)}

$$
\begin{gathered}
X=[a, b]=G \frac{\left(c_{X}, r_{X}\right)}{A(X)} ; \\
c_{X}=\frac{a+b}{2}, \quad r_{X}=\frac{b-a}{2}, A(X)=b-a \\
-Y=-[c, d]=[-d,-c]=G \frac{\left(c_{-Y}, r_{-Y}\right)}{A(-Y)} ; \\
c_{-Y}=\frac{-d+(-c)}{2}, \quad r_{X}=\frac{-c-(-d)}{2}, \\
A(Y)=-c-(-d)
\end{gathered}
$$

$X-Y=X+(-Y)=[a, b]+[-d,-c]=[a-d, b-c]$

$$
=G \frac{\left(c_{X-Y}, r_{X-Y}\right)}{A(X-Y)} \text {, where }
$$

$c_{X-Y}=\frac{1}{2}(a-d+b-c)=\frac{1}{2}(a+b)-\frac{1}{2}(c+d)=c_{X}-c_{Y}$

$r_{X+Y}=\frac{1}{2}((b-c)-(a-d))=\frac{1}{2}(b-a)+\frac{1}{2}(d-c)=r_{X}+r_{Y}$ $A(X+Y)=(b-c)-(a-d)=(b-a)+(d-c)=A(X)+A(Y)$.

6. Division operation

$$
X=G \frac{\left(c_{X}, r_{X}\right)}{A(X)} \text { and } Y=G \frac{\left(c_{Y}, r_{Y}\right)}{A(Y)}
$$

G-numbers on (n)

$$
\frac{X}{Y}=X \cdot \frac{1}{Y}=G \frac{\left(\frac{c_{X} c_{Y}+r_{X} r_{Y}}{c_{Y}^{2}-r_{Y}^{2}}, \frac{c_{X} r_{Y}+r_{X} c_{Y}}{c_{Y}^{2}-r_{Y}^{2}}\right)}{\frac{c_{X} A(Y)+c_{Y} A(X)}{c_{Y}^{2}-r_{Y}^{2}}}
$$




$$
\begin{aligned}
& \text { Example } \\
& 1 \\
& \frac{X}{Y}=X \cdot \frac{1}{Y}=[a, b] \cdot\left[\frac{1}{d}, \frac{1}{c}\right]=\left[\frac{a}{d}, \frac{b}{c}\right]=G \frac{\left(c_{X}, r_{Y}\right)}{A\left(\frac{X}{Y}\right)} \text {, where } \\
& c_{\bar{Y}}=\frac{1}{2}\left(\frac{a}{d}+\frac{b}{c}\right)=\frac{1}{2}\left(\frac{a c+b d}{c d}\right)=\left(\frac{2 a c+2 b d}{4 c d}\right) \\
& =\frac{(a c+b c+a d+b d)+(b d-b c-a d+a c)}{\left(c^{2}+d^{2}+2 c d\right)-\left(c^{2}+d^{2}-2 c d\right)} \\
& =\frac{\frac{(a+b)(c+d)}{4}+\frac{(b-a)(d-c)}{4}}{\left(\frac{c+d}{2}\right)^{2}-\left(\frac{d-c}{2}\right)^{2}} \\
& =\frac{c_{X} \cdot c_{Y}+r_{X} \cdot r_{Y}}{c_{Y}^{2}-r_{Y}^{2}} \\
& r_{\bar{Y}}=\frac{1}{2}\left(\frac{b}{c}-\frac{a}{d}\right)=\frac{1}{2}\left(\frac{b d-a c}{c d}\right)=\left(\frac{2 b d-2 a c}{4 c d}\right) \\
& =\frac{(a d-a c+b d-b c)+(b c+b d-a c-a d)}{\left(c^{2}+d^{2}+2 c d\right)-\left(c^{2}+d^{2}-2 c d\right)} \\
& =\frac{\frac{(a+b)(d-c)}{4}+\frac{(b-a)(c+d)}{4}}{\left(\frac{c+d}{2}\right)^{2}-\left(\frac{d-c}{2}\right)^{2}} \\
& =\frac{c_{X} \cdot r_{Y}+r_{X} \cdot c_{Y}}{c_{Y}^{2}-r_{Y}^{2}} \\
& A\left(\frac{X}{Y}\right)=\left(\frac{b}{c}-\frac{a}{d}\right)=\left(\frac{b d-a c}{c d}\right)=\left(\frac{2 b d-2 a c}{2 c d}\right) \\
& =\frac{\frac{(a d-a c+b d-b c)}{2}+\frac{(b c+b d-a c-a d)}{2}}{\frac{\left(c^{2}+d^{2}+2 c d\right)}{4}-\frac{\left(c^{2}+d^{2}-2 c d\right)}{4}} \\
& =\frac{\frac{(a+b)}{2} \cdot(d-c)+\frac{(c+d)}{4} \cdot(b-a)}{\left(\frac{c+d}{2}\right)^{2}-\left(\frac{d-c}{2}\right)^{2}} \\
& =\frac{c_{X} \cdot A(Y)+c_{Y} \cdot A(Y)}{c_{Y}^{2}-r_{Y}^{2}} \text {. }
\end{aligned}
$$

\section{Granular transformation functions for dealing with heterogeneous information}

In decision-making problem, experts prefer to express their opinions in predefined numerical and linguistic domain due to quantitative and qualitative aspects of the criteria. This section shows transformation function to unify linguistic, numerical, and interval-valued information's into a common homogenous function (Herrera and Martinez 2000) without loss of information and vice versa. It improves the comprehension and evaluation of the results, and simplifies the unification procedures involving a small number of transformation steps. As per Alsawy and Hefny (2013b), the details are given in the following:

\subsection{Transforming interval number into G-number and vice versa}

Any interval number $X=[a, b]$ can be transformed into its equivalent G-number form: $X=G \frac{\left(c_{X}, r_{X}\right)}{A(X)}$, where $c_{X}=\frac{(a+b)}{2}$ is the center value of $X, r_{X}=\frac{(b-a)}{2}$ is the radius of $X$, and $A(X)=(b-a)$ is the area of $X$. As shown in Fig. 1, the G-number $X=G \frac{\left(c_{X}, r_{X}\right)}{A(X)}$ can be transformed to Interval number $X=I[a, b], \quad$ where $a=\left(c_{X}-r_{X}\right), \quad b=\left(c_{X}+r_{X}\right)$.

\subsection{Transforming triangular fuzzy number (TFN) into G-number and vice versa}

The TFN $X=\operatorname{Tri}(a, b, c)$ with membership function $\mu_{X}(x)=\max \left(\min \left(\frac{x-a}{b-a}, \frac{c-x}{c-b}\right), 0\right)$ can be transformed to equivalent G-number form: $X=G \frac{\left(c_{X}, r_{X}\right)}{A(X)}$, where $c_{X}=\frac{(a+c)}{2}$ is the center value of $X, r_{X}=\frac{(c-a)}{2}$ is the radius of $X$, and $A(X)=\frac{(c-a)}{2}$ is the area of $X$. As shown in Fig. 2, the granular number $X=G \frac{\left(c_{X}, r_{X}\right)}{A(X)}$ can be transformed to TFN $X=\operatorname{Tri}(a, b, c)$, $a=\left(c_{X}-r_{X}\right), \quad b=b_{1}, \quad c=\left(c_{X}+r_{X}\right)$.

where

\subsection{Transforming trapezoidal fuzzy number (TrFN) into G-number and vice versa}

Any $\operatorname{TrFN} X=\operatorname{Trap}(a, b, c, d)$ with membership function $\mu_{X}(x)=\max \left(\min \left(\frac{x-a}{b-a}, 1, \frac{c-x}{c-b}\right), 0\right)$ can be transformed to its equivalent unified G-number form: $X=G \frac{\left(c_{X}, r_{X}\right)}{A(X)}$, where $c_{X}=\frac{(d+a)}{2}$ is the center value of $X$, $r_{X}=\frac{(d-a)}{2}$ is the radius of $X$, and $A(X)=\left(\frac{(d-a)+(c-b)}{2}\right)$ is the area of $X$.

As shown in Fig. 3, the G-number $X=G \frac{\left(c_{X}, r_{X}\right)}{A(X)}$ can be transformed to $\operatorname{TrFNs} X=\operatorname{Tr}(a, b, c, d)$, where $a=\left(c_{X}-r_{X}\right), \quad b=b_{2}, \quad c=c_{2}, \quad d=\left(c_{X}+r_{X}\right)$.

\subsection{Transforming rough number into G-number and vice versa}

Any rough number $X=(\underline{X}, \bar{X})=([a, b],[c, d])$ can be transformed into G-number as $X=G \frac{\left(c_{X}, r_{X}\right)}{A(X)}$, where $c_{x}=\frac{(c+d)}{2}$ and $r_{X}=\left[\left(d-c_{X}\right)\right.$ or $\left.\left(c_{X}-c\right)\right]$ represent the center value and the radius of upper approximate $\bar{X}$. In the case of rough number, there are lower approximation length $L(\underline{X})$ and upper approximation length $L(\bar{X})$. Since 


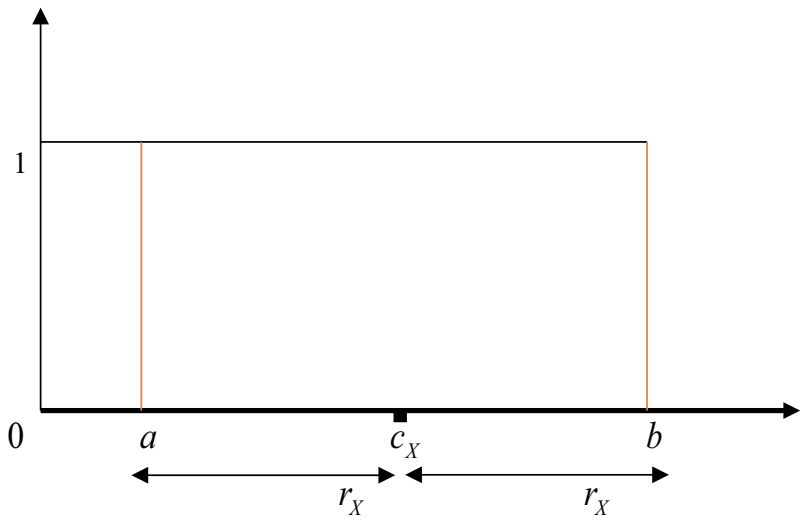

Fig. $1 X=I\left(c_{X}-r_{X}, c_{X}+r_{X}\right)$

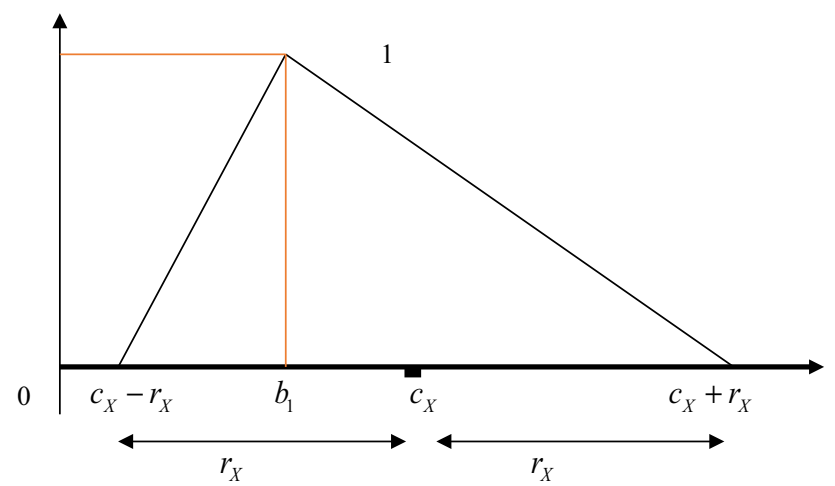

Fig. $2 X=\operatorname{Tri}\left(c_{X}-r_{X}, b_{1}, c_{X}+r_{X}\right)$

$A(X)$ represents weight of number $X$, it is represented in G-number as average of these two lengths:

$A(X)=\frac{1}{2}(L(\underline{X})+L(\bar{X}))=\left(\frac{(b-a)+(c-d)}{2}\right)$.

From Fig. 4, the transformation from G-number to the rough number can be shown clearly.

\subsection{Transforming crisp number into G-number and vice versa}

For any crisp number $X$, its equivalent G-number is: $X=G \frac{(X, 0)}{0}$, where $c_{X}=X$ is the center value of $X, r_{X}=0$ is the radius of $X$, and $A(X)=0$ is the area of $X$.

The same formula $X=G \frac{(X, 0)}{0}$ could be deducted from equivalent G-number for various uncertain numbers, described in the following (Alsawy and Hefny 2013b):

1. For Interval number Setting upper limit ' $a$ ' and lower limit ' $b$ ' for the interval by the same number $X$.

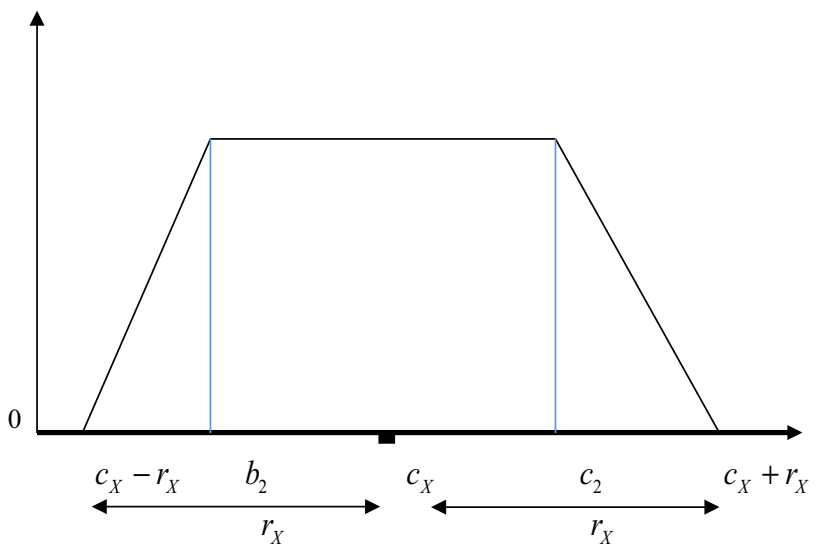

Fig. $3 X=\operatorname{Tr}\left(c_{X}-r_{X}, b_{2}, \quad c_{2}, c_{X}+r_{X}\right)$

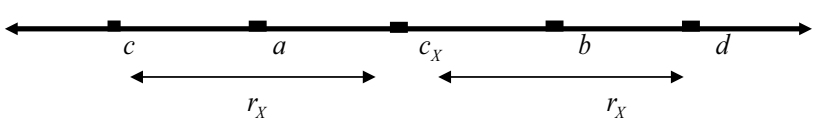

Fig. $4 X=R\left([a, b],\left[c_{X}-r_{X}, c_{X}+r_{X}\right]\right)$

2. For fuzzy number Setting its support by zero.

3. For rough number Setting upper and lower approximations by the same exact number.

\section{Comparison of G-number}

As per Alsawy and Hefny (2013a), in representing various types of uncertain granular numbers, unified granular number (UGN) or simply granular number $(\mathrm{G})$ does not neglect the membership function, which is the main idea of the fuzzy set. Even G-number represents the fuzzy number using two parameters of $G\left(c_{X}, r_{X}\right)$ one being the center $c_{X}$ and another radius $r_{X}$ of that domain (granular), respectively. In addition, weight $A(X)\left(0<|A(X)| \leq 2\left|r_{X}\right|\right)$ representing weight in the improved version of unified granular number (UGN) $X=G \frac{\left(c_{X}, r_{X}\right)}{A(X)}$ distinguishes among different numbers within the same boundaries.

The following steps are detailed in comparison between two G-numbers, say $X=G \frac{\left(c_{X}, r_{X}\right)}{A(X)}$ and $Y=G \frac{\left(c_{Y}, r_{Y}\right)}{A(Y)}$.

Step 1 First, we have to check whether the corresponding weight $A(X)$ and $A(Y)$ lies in that domain $\left(0 \leq|A(X)| \leq 2\left|r_{X}\right|\right)$ and $\left(0 \leq|A(Y)| \leq 2\left|r_{Y}\right|\right)$, respectively, or not. If yes, then we proceed to the next step; otherwise, the experts will make modification in the decision matrix. 
Step 2 Next, we will check which of the rule described in Eq. (9), and it is satisfied for comparing the above G-numbers $X=G \frac{\left(c_{X}, r_{X}\right)}{A(X)}$ and $Y=G \frac{\left(c_{Y}, r_{Y}\right)}{A(Y)}$. If any of the rules are not applicable, experts will make modification in the decision matrix, until both Steps 1 and 2 are satisfied:

Rule:1 If $c_{X}>c_{Y}$ and $r_{X}>r_{Y}$ then $X>Y$

Rule:2 If $c_{X}<c_{Y}$ and $r_{X}<r_{Y}$ then $X<Y$

Rule:3 If $c_{X} \approx c_{Y}, \quad r_{X} \approx r_{Y}$ and $A(X)>A(Y)$ then $\left.X>Y\right\}$.

Rule:4 If $c_{X} \approx c_{Y}, \quad r_{X} \approx r_{Y}$ and $A(X)=A(Y)$ then $X=Y$

Rule:5 If $c_{X} \approx c_{Y}, \quad r_{X} \approx r_{Y}$ and $A(X)<A(Y)$ then $X<Y$

\section{For}

example,

$X=G \frac{(0.2073,0.2020)}{0.1814}$ and $Y=G \frac{(0.2079,0.2022)}{0.212}$.

let

Here, $\quad\left[A(X) \mid=0.1814\right.$ and $2\left|r_{X}\right|^{2}=0.4040 \quad$ and $|A(Y)|=0.2212$ and $2\left|r_{Y}\right|=0.4044$. Hence, the validity of Step 1 is checked.

Next, we take the center value, radius value, and weight of granular (domain) numbers, and check which rules (Rule 1-5) proposed in Step 2 are applicable, for this problem.

Here, Rule 5 is applicable, and since $A(X)<A(Y)$, then $X<Y$.

\section{Proposed Granulation function for managing non-homogeneous linguistic information}

Consider a group decision-making (GDM) problem, for a group of two or more decision makers, characterized by their own preferences, who use a granular preference relation to express their opinions about a set of criteria and alternatives in classifying them from best to worst (Pedrycz and Chen 2015a). Here, information granularity is an important modeling assent, which brings forward an ability of the decision maker to exercise some flexibility to be used in modifying his/her positions when becoming aware of preferences of other members of the group (Pedrycz and Song 2011). An important issue in decision making corresponding to the level of discrimination among distinct degree of uncertainties is to analyze the granularity of uncertainty (Dubois and Prade 2016). In this paper, we are discussing information granules in the heterogeneous mode to be used as inputs in decision-making matrix, and to emphasize this, we proposed the following granulation function in Eq. (10) to elevate the preference relation to its multi-granular format in complex systems working in openworld environment:

$\Delta=(\mathrm{Z}, \tilde{a})$,

where $\mathrm{Z}$ stands for a specific heterogeneous(multi-granular) information granule used here (for instance, intervals, fuzzy sets, rough sets, and alike), and $\tilde{a}$ stands for its corresponding scaling, defined in Table 1, for inputs to be given by multiple experts.

- We use the following set of nine scaling $(\tilde{1}-\tilde{9})$ to provide the expert preferences, which can take linguistic preferences as per the problem set (Table 1).

- The proposed granulation function $\Delta=(\mathrm{Z}, \tilde{a})$ helps translate linguistic terms into meaningful non-homogeneous information granules, so that the highest performance index is achieved.

In this paper, for criteria weights, we have taken linguistic terms defined in Table 2, and for selecting alternatives, the linguistic terms are in Table 3 . The flexibility offered by the level of granularity can be proven effective in modeling problem involving several experts with different knowledge levels, since to describe each item with different precision, they need more than one linguistic term set.

\section{Granular analytic hierarchy process (G-AHP) for criteria weighting}

\subsection{An overview}

Our study concerns an extension of AHP to the group decision making (GDM) with the admitted level of granularity giving rise to a granular reciprocal matrix. The muchneeded flexibility is brought into the AHP structure by allowing entries in reciprocal matrices to be information granules (intervals, fuzzy numbers, and rough numbers) rather than numeric entities (Pedrycz and Song 2011). The multi-granular entries (Intervals, fuzzy numbers, or rough numbers) supply a required flexibility in selecting the most appropriate numeric representative of the reciprocal matrix with a focus on forming an aggregate of the reciprocal matrices. Pedrycz and Song (2014) were concerned with information granulation (present in the problem of AHP) in the characterization of pairwise assessment of alternatives for decision-making problems minimizing inconsistency index by suitable mapping of linguistic scale.

\subsection{Algorithmic procedure of the method}

Let for a group decision-making (GDM) problem, $A_{i}(i=1,2, \ldots, m)$ be the finite set of alternatives, to evaluate with respect to the set of criteria $C_{j}(j=1,2, \ldots, n)$ by a group of $k$ decision makers $E_{p}(p=1,2, \ldots, k)$, using a collection of multi-granular linguistic information. The above calculation process involves two phases. The first phase evaluates and prioritizes the criteria weight through granular AHP involving pairwise decision matrix 
Table 1 Scaling of corresponding G-numbers

\begin{tabular}{llllll}
\hline Scaling & $C(a)$ & $T(a, b, c)$ & $\mathrm{I}[a, b]$ & $T r(\mathrm{a}, \mathrm{b}, \mathrm{c}, \mathrm{d})$ & $R(b,[a, c])$ \\
\hline$\tilde{1}$ & 1 & $(0,1,2)$ & {$[0,2]$} & $(0,0,2,3)$ & $(1,[0,2])$ \\
$\tilde{3}$ & 3 & $(2,3,4)$ & {$[2,4]$} & $(1,2,4,5)$ & $(3,[2,4])$ \\
$\tilde{5}$ & 5 & $(4,5,6)$ & {$[4,6]$} & $(3,4,6,7)$ & $(5,[4,6])$ \\
$\tilde{7}$ & 7 & $(6,7,9)$ & {$[6,8]$} & $(5,6,8,9)$ & $(7,[6,8])$ \\
$\tilde{9}$ & 9 & $(8,9,10)$ & {$[8,10]$} & $(7,8,10,10)$ & $(9,[8,10])$ \\
\hline
\end{tabular}

$\tilde{2}, \tilde{4}, \tilde{6}$, and $\tilde{8}$ are intermediate values

$\frac{1}{\tilde{a}}$ represents the corresponding reciprocal values of $\tilde{a}(\tilde{1}-\tilde{9})$

$C$ crisp number, $T$ triangular fuzzy number (TFN ), $I$ interval number, $R$ rough number, $\operatorname{Tr}$ Trapezoidal fuzzy number (TrFN)

Table 2 Measurement scale for pairwise comparisons in criteria

\begin{tabular}{lll}
\hline Linguistic preference & Abbreviation & $\begin{array}{l}\text { Numeri- } \\
\text { cal } \\
\text { rating }\end{array}$ \\
\hline Equally preferred & EP & $\tilde{1}$ \\
Moderately preferred & MO & $\tilde{3}$ \\
Strongly preferred & SP & $\tilde{5}$ \\
Very strongly preferred & VP & $\tilde{7}$ \\
Extremely preferred & XP & $\tilde{9}$ \\
\hline
\end{tabular}

$* \tilde{2}, \tilde{4}, \tilde{6}, \tilde{8}$ are intermediate value

Table 3 Linguistic terms and corresponding ratings for each alternative

\begin{tabular}{lll}
\hline Linguistic terms & Abbreviation & $\begin{array}{l}\text { Numeri- } \\
\text { cal } \\
\text { rating }\end{array}$ \\
\hline Very poor & VP & $\tilde{1}$ \\
Medium poor & MP & $\tilde{3}$ \\
Fair & F & $\tilde{5}$ \\
Medium good & MG & $\tilde{7}$ \\
Very good & VG & $\tilde{9}$ \\
\hline
\end{tabular}

having a heterogeneous data set. Second, assuming for the problem assigned, the comparison ratios determined by experts with different uncertainty levels in the same problem. This algorithmic procedure suggests converting all uncertain values into homogenous granular number form, so that the arithmetic operations can be properly utilized. Let $w_{j}(j=1,2, \ldots, n)$ be a set of the weight vectors for criteria set $C_{j}(j=1,2, \ldots, n)$ evaluated through granular AHP, satisfying $w_{j} \geq 0$ and $\sum_{j=1}^{n} w_{j}=1$ The steps of the proposed method involve the following steps:

Step 1 Formation of a heterogeneous granular reciprocal matrix and allocation of information granules.
An expert group $E_{p}(p=1,2, \ldots, k)$ is created from a pool of $k$ experts to form linguistic preference data and two sessions of data collection are conducted. In the first session, experts $E_{p}(p=1,2, \ldots, k)$ rate the identified criteria pairwise in comparison matrices, using a nine-point linguistic scale (Table 2). In the second session, the linguistic comparison variables are converted to multi-granular information $(\mathrm{Z}, \tilde{a})^{p}$, defined in Table 1, to represent different types of uncertainties and forming heterogeneous granular decision matrices $\hat{R}^{p}$ for respective expert group $E_{p}(p=1,2, \ldots, k)$ :

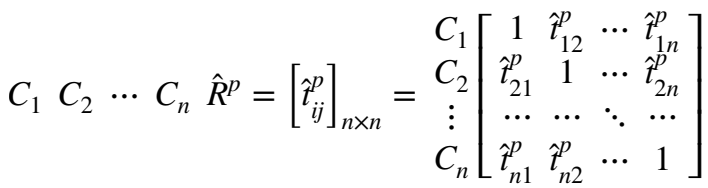

$$
\begin{aligned}
& \text { where each } \hat{t}_{i j}^{p}=(\mathrm{Z}, \tilde{a})^{p} \text {. }
\end{aligned}
$$

Here, $\hat{t}_{j i}^{p}$ being the reciprocal of $\hat{t}_{i j}^{p}(i, j=1,2, \ldots, n)$. Here, expected values of all heterogeneous granular numbers are calculated (for checking consistency of the granular reciprocal matrix). If CR (consistency ratio) is less than 0.1 (Threshold value), then the granular reciprocal matrices are consistent; otherwise, the experts will make an adjustment in their decision-making.

Step 2 Making the multi-granular information uniform.

All multi-granular linguistic performances $\hat{t}_{i j}^{p}=(\mathrm{Z}, \tilde{a})^{p}$ ingroup decision matrices (GDM) $\hat{R}^{p}$ for different experts $E_{p}(p=1,2, \ldots, k)$ are transformed to its homogeneous linguistic domain viz. Granular-number, using operations defined in sub-Sects. (3.1-3.5). Thus, uniform granular reciprocal matrices $M^{p}=\left[g_{i j}^{p}\right]_{n \times n}$ for criteria pairwise comparison are formed corresponding to the values $g_{i j}^{p}(p=1,2, \ldots, k)$. Details are given in Eqs. (12-13):

$$
\begin{aligned}
& \begin{array}{llll}
C_{1} & C_{2} & \cdots & C_{n}
\end{array}
\end{aligned}
$$

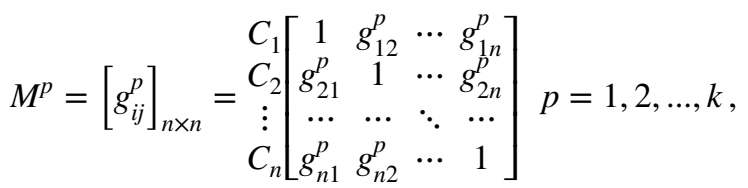

$$
\begin{aligned}
& \text { where } g_{i j}^{p}=G \frac{\left(c_{i j}^{p}, r_{i j}^{p}\right)}{A\left(\hat{t}_{i j}^{p}\right)} \text {. }
\end{aligned}
$$

For example: 


$$
\begin{aligned}
\hat{t}_{11}^{1}= & (T, \tilde{8})=(7,8,9) \quad g_{11}^{1}=G \frac{\left(c_{\hat{t}_{11}^{1}}, r_{\hat{t}_{11}^{1}}\right)}{A\left(\hat{t}_{11}^{1}\right)} \\
& =G \frac{\left(\frac{9+7}{2}, \frac{9-7}{2}\right)}{\frac{9-7}{2}}=G \frac{(8,1)}{1} \\
\hat{t}_{11}^{1}= & (I, \tilde{3})=[2,4] \\
& =G \frac{\left(\frac{2+4}{2}, \frac{4-2}{2}\right)}{4-2}=G \frac{(3,1)}{1} .
\end{aligned}
$$

Step 3 Aggregation phase.

Here, the focus is on aggregating the information granules $g_{i j}^{p}$ of the reciprocal matrices $M^{p}$ (Eq. 12). All the homogeneous granular number (G-number) entries $g_{i j}^{p}(p=1,2, \ldots, k)$ are fused, and a collective linguistic performance $\hat{g}_{i j}$ is obtained by aggregation of the above-mentioned values, as shown in Eqs. (15-16). Based on which the above aggregated granular matrix $\hat{H}=\left[\hat{g}_{i j}\right]_{n \times n}$ is formed, as shown in Eq. (14):

$$
\begin{aligned}
& \begin{array}{llll}
C_{1} & C_{2} & \cdots & C_{n}
\end{array} \\
& \hat{H}=\left[\hat{g}_{i j}\right]_{n \times n}=\begin{array}{c}
C_{1} \\
C_{2} \\
\vdots \\
C_{n}
\end{array}\left[\begin{array}{cccc}
1 & \hat{g}_{12} & \cdots & \hat{g}_{1 n} \\
\hat{g}_{21} & 1 & \cdots & \hat{g}_{2 n} \\
\cdots & \cdots & \ddots & \cdots \\
\hat{g}_{n 1} & \hat{g}_{n 2} & \cdots & 1
\end{array}\right] \text {, }
\end{aligned}
$$

where $\hat{g}_{i j}\left(=\frac{1}{k} \sum_{p} g_{i j}^{p}\right)=G \frac{\left(c_{\hat{g}_{i j}}, r_{\hat{g}_{i j}}\right)}{A\left(\hat{g}_{i j}\right)}$,

$$
\left\{\begin{array}{l}
c_{\hat{g}_{i j}}=\frac{1}{k} \sum_{p=1}^{k} c_{\hat{t}_{i j}^{p}} \\
r_{\hat{g}_{i j}}=\frac{1}{k} \sum_{p=1}^{k} r_{\hat{t}_{i j}^{p}} \\
A\left(\hat{g}_{i j}\right)=\frac{1}{k} \sum_{p=1}^{k} A\left(\hat{t}_{i j}^{p}\right)
\end{array} .\right.
$$

For the diagonal element in the reciprocal matrix $\hat{H}$, its equivalent G-number is obtained from a transformation operator, which is defined in sub-Sect. 3.5. To get the ranking of criteria, we apply summation (Step 4) and normalization (Step 5) of the criterion respectively, described in the following.

Step 4 Compute sum of each row $\sum_{j} \hat{g}_{i j}$ in the comparison matrix $\hat{H}$, to get a $n \times 1$ matrix $\bar{H}$, as shown in Eq. (17). Here, center value $c_{g_{i}}$, radius value $r_{g_{i}}$, and the weight value $A\left(g_{i}\right)$ of each granular elements $g_{i}(i=1,2, \ldots, n)$ in matrix $\bar{H}$ are calculated, as per operations detailed in Eqs. $(18,19)$ :
$\bar{H}=\left[g_{i}\right]_{n \times 1}=\begin{gathered}C_{1} \\ C_{2} \\ \vdots \\ C_{n}\end{gathered}\left[\begin{array}{c}g_{1} \\ g_{2} \\ \vdots \\ g_{n}\end{array}\right]_{n \times 1}$,

where $g_{i}\left(=\sum_{j} \hat{g}_{i j}\right)=G \frac{\left(c_{g_{i}}, r_{g_{i}}\right)}{A\left(g_{i}\right)}$,

$c_{g_{i}}=\sum_{j} c_{g_{i j}}$

$\left.\begin{array}{l}r_{g_{i}}=\sum_{j} r_{g_{i j}} \\ A\left(g_{i}\right)=\sum_{j} A\left(g_{i j}\right)\end{array}\right\}$.

Step 5 Normalize the criteria values in matrix $\bar{H}$.

First, take the summations of center value $c_{g_{i}}$, radius value $r_{g_{i}}$, and the weight value $A\left(g_{i}\right)$ of value $g_{i}$ for each criterion $C_{i}(i=1,2, \ldots, n)$ in matrix $\bar{H}$. Details are given in Eqs. (20, 21):

$\sum_{i} g_{i}=g_{\hat{p}}=G \frac{\left(c_{g_{\hat{p}}}, r_{g_{\hat{p}}}\right)}{A\left(g_{\hat{p}}\right)}$,

where

$\left.\begin{array}{l}c_{g_{\hat{p}}}=\sum_{i} c_{g_{i}} \\ r_{g_{\hat{p}}}=\sum_{i} r_{g_{i}} \\ A\left(g_{\hat{p}}\right)=\sum_{i} A\left(g_{i}\right)\end{array}\right\}$.

As per Eq. (22), the normalized values $w_{i}(i=1,2, \ldots, n)$ in matrix $\tilde{H}$ for each criteria $C_{i}(i=1,2, \ldots, n)$ are calculated by dividing center value $c_{g_{i}}$, radius value $r_{g_{i}}$, and the weight value $A\left(g_{i}\right)$ of granular number $g_{i}(i=1,2, \ldots, n)$ by its respective summation values $g_{\hat{p}}$. The computations are shown in Eqs. $(23,24)$ :

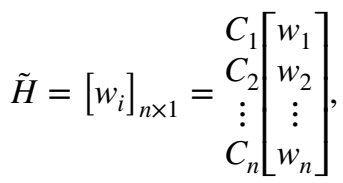

where each

$w_{i}=G \frac{\left(c_{w_{i}}, r_{w_{i}}\right)}{A\left(w_{i}\right)}$ and, 
$\left.\begin{array}{l}c_{w_{i}}=\left(c_{g_{i}} / c_{g_{\hat{p}}}\right) \\ r_{w_{i}}=\left(r_{g_{i}} / r_{g_{\hat{p}}}\right) \\ A\left(w_{i}\right)=\left(A\left(g_{i}\right) / A\left(g_{\hat{p}}\right)\right)\end{array}\right\}$.

Step 6 Ranking of the criteria.

Then, depending on the problem scenario, the criteria $C_{i}(i=1,2, \ldots, n)$ are prioritized accordingly as per its normalized granular weights $w_{i}(i=1,2, \ldots, n)$.

\section{Granular VIKOR (G-VIKOR) for alternative evaluation}

\subsection{Brief description}

VIKOR is one of the classical MCDM techniques and regarded as an efficient tool in finding a compromise solution emerging out of a set of conflicting criteria (Qin et al. 2015). In this section, we develop an extended VIKOR for solving multi-attribute decision-making (MADM) problems under heterogeneous information granules. When determining the exact values of the criteria is difficult, G-numbers can prove to be very useful tools to deal with uncertainty of a heterogeneous nature, in which each criterion can be described in terms of a G-number in keeping with the opinions of decision makers. In this study, we assume that for a given collection of linguistic terms (Table 3), all the decision makers (DMs) select the linguistic terms to give linguistic values, so that they can express their decision preferences in the form of G-numbers. Table 3, shows a collection of linguistic terms from "very poor (VP)" to "very good (VG)" and their corresponding granular information.

\subsection{Algorithmic framework of the proposed method}

In general, the MCDM problem involves a process of selecting the best alternative from a set of feasible alternatives with respect to multiple attributes based on a set of conflicting attributes. Let for a group decision-making (GDM) problem, $A_{i}(i=1,2, \ldots, m)$ be the finite set of $m$ alternatives, to be evaluated with respect to the set of criteria $C_{j}(j=1,2, \ldots, n)$ by a group of $k$ decision makers $E_{p}(p=1,2, \ldots, k)$, using a collection of multi-granular linguistic information. Let $w_{j}(j=1,2, \ldots, n)$ be a set of the weight vectors for criteria set $C_{j}(j=1,2, \ldots, n)$ evaluated through granular AHP, satisfying $w_{j} \geq 0$ and $\sum_{j=1}^{n} w_{j}=1$.
The extended VIKOR approach based on heterogeneous information granules involves the following steps:

Step 1 Determine the initial group decision matrices.

Similar to Step 1 of sub-sect. 6.2, two sessions of data collection are done by the same group of experts $E_{p}(p=1,2, \ldots, k)$. First, the experts rate the alternatives $A_{i}(i=1,2, \ldots, m)$ with respect to $C_{j}(j=1,2, \ldots, n)$ in the pairwise comparison matrices in linguistic mode, as defined in Table 3. In the second session, the linguistic data are converted to its multi-granular counterparts $(\mathrm{Z}, \tilde{a})^{p}$ as per choice of experts group $E_{p}(p=1,2, \ldots, k)$, thus forming a group of initial decision matrices $D^{p}=\left[d_{i j}^{p}\right]_{m \times n}$. The details are shown in Eqs. $(25,26)$ :

$$
\begin{aligned}
& \begin{array}{lllll}
C_{1} & C_{2} & \cdots & C_{n}
\end{array} \\
& D^{p}=\left[d_{i j}^{p}\right]_{m \times n}=\begin{array}{c}
A_{1} \\
A_{2} \\
\vdots \\
A_{m}
\end{array}\left[\begin{array}{cccc}
d_{11}^{p} & d_{12}^{p} & \cdots & d_{1 n}^{p} \\
d_{21}^{p} & d_{22}^{p} & \cdots & d_{2 n}^{p} \\
\cdots & \cdots & \ddots & \cdots \\
d_{m 1}^{p} & d_{m 2}^{p} & \cdots & d_{m n}^{p}
\end{array}\right] ;
\end{aligned}
$$

where $d_{i j}^{p}=(\mathrm{Z}, \tilde{a})^{p}$.

For example: $\left\{\begin{array}{l}d_{11}^{1}=(T, \tilde{8})^{1}=(7,8,9) \\ d_{12}^{1}=(I, \tilde{3})^{1}=(2,4)\end{array}\right.$

- $d_{i j}^{p}$ in Eq. (26) represents rating of the $A_{i}$ with respect to $C_{j}(j=1,2, \ldots, n)$, for $p^{\text {th }}$ expert, while

- Zstands for heterogeneous information granule and $\tilde{a}$ its corresponding scaling (Table 1).

Step 2 Making the information granules uniform.

The heterogeneous linguistic granules $\left(d_{i j}^{p}\right)$ in Eq. (26) are first transformed into unified granular numbers $\left(e_{i j}^{p}\right)$, shown in Eq. (28), to be used as inputs in uniform group decision matrices $\left(J^{p}\right)$ in Eq. (27). The values $c_{d_{i j}^{p}}, r_{d_{i j}^{p}}$ and $A\left(d_{i j}^{p}\right)$, respectively, in respect to $e_{i j}^{p}$ [in Eq. (28)] are calculated based on granular transformation functions, as defined in sub-sects. 3.1-3.5.

$$
\begin{aligned}
& \begin{array}{lllll}
C_{1} & C_{2} & \cdots & C_{n}
\end{array}
\end{aligned}
$$

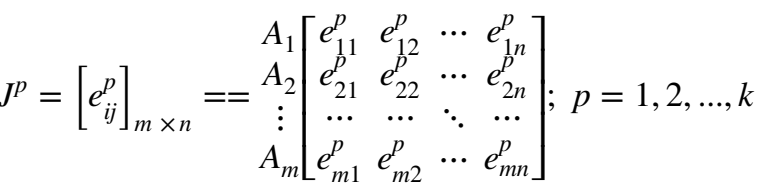

$$
\begin{aligned}
& \text { where } \quad e_{i j}^{p}=G \frac{\left(c_{d_{i j}^{p}}, r_{d_{i j}^{p}}\right)}{A\left(d_{i j}^{p}\right)} \text {. }
\end{aligned}
$$


Step 3 Aggregation phase.

Using Eq. (23), experts' individual uniform preferences $e_{i j}^{p}(p=1,2, \ldots, k)$, in Eq. (28), are further transform to its aggregated form $\left(l_{i j}\right)$, shown in Eqs. (30-31), that are used as inputs in a collective performance matrix $(\hat{L})$ in Eq. (29).

$$
\begin{array}{llll}
C_{1} & C_{2} & \cdots & C_{n}
\end{array}
$$

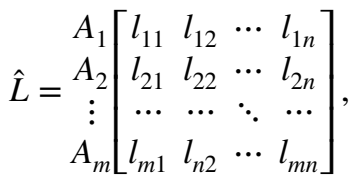

where $l_{i j}=\left(\frac{1}{k} \sum_{p} e_{i j}^{p}\right)=G \frac{\left(c_{l_{i j}}, r_{l_{i j}}\right)}{A\left(l_{i j}\right)}$,

$$
\left\{\begin{array}{l}
c_{l_{i j}}=\frac{1}{k} \sum_{p=1}^{k} c_{d_{i j}^{p}} \\
r_{l_{i j}}=\frac{1}{k} \sum_{p=1}^{k} r_{d_{i j}^{p}} \\
A\left(l_{i j}\right)=\frac{1}{k} \sum_{p=1}^{k} A\left(d_{i j}^{p}\right)
\end{array}\right.
$$

Step 4 Determine the best value $f_{j}^{*}$ and the worst value $f_{j}^{-}$ of each criterion function in matrix $(\hat{L})$.

For the benefit criterion which belongs to the "larger-thebetter" category: $f_{j}^{*}=\max _{i} l_{i j}, f_{j}^{-}=\min _{i} l_{i j}$; For the cost criterion which belongs to the "smaller-the-better" category: $f_{j}^{*}=\min _{i} l_{i j}, f_{j}^{-}=\max _{i} l_{i j}$. Details are given in Eqs. (32-33):

$$
\begin{aligned}
& c_{f_{j}^{*}}=\max _{i} c_{l_{i j}} ; \quad c_{f_{j}^{-}}=\min _{i} c_{l_{i j}} \\
& r_{f_{j}^{*}}=\max _{i} r_{l_{i j}} ; r_{f_{j}^{-}}=\min _{i} r_{l_{i j}} \\
& A\left(f_{j}^{*}\right)=\max _{i} A\left(l_{i j}\right) ; A\left(f_{j}^{-}\right)=\min _{i} A\left(l_{i j}\right)
\end{aligned}
$$

Step 5 Calculate the values $S_{i}$ and $R_{i}(i=1,2, \ldots \ldots . m)$ expressed by the following relations:

$$
\begin{aligned}
& S_{i}=\sum_{j \in B}\left[w_{j}\left(f_{j}^{*}-l_{i j}\right) /\left(f_{j}^{*}-f_{j}^{-}\right)\right]+\sum_{j \in C}\left[w_{j}\left(l_{i j}-f_{j}^{*}\right) /\left(f_{j}^{-}-f_{j}^{*}\right)\right], \\
& R_{i}=\left\{\begin{array}{l}
\max _{j \in B} w_{j}\left(f_{j}^{*}-l_{i j}\right) /\left(f_{j}^{*}-f_{j}^{-}\right) \\
\max _{j \in C} w_{j}\left(l_{i j}-f_{j}^{*}\right) /\left(f_{j}^{-}-f_{j}^{*}\right)
\end{array},\right. \\
& \text { For } \sum_{j \in B}\left[w_{j}\left(f_{j}^{*}-l_{i j}\right) /\left(f_{j}^{*}-f_{j}^{-}\right)\right] \text {, } \\
& \left.\begin{array}{l}
\left(f_{j}^{*}-l_{i j}\right)=G \frac{\left(c_{f_{j}^{*}}-c_{l_{i j}}, r_{f_{j}^{*}}+r_{l_{i j}}\right)}{A\left(f_{j}^{*}\right)+A\left(l_{i j}\right)} ; \\
\left(f_{j}^{*}-f_{j}^{-}\right)=G \frac{\left(c_{f_{j}^{*}}-c_{f_{j}^{-}}, r_{f_{j}^{*}}+r_{f_{j}^{*}}\right)}{A\left(f_{j}^{*}\right)+A\left(f_{j}^{-}\right)}
\end{array}\right\}, \\
& \therefore \frac{\left(f_{j}^{*}-l_{i j}\right)}{\left(f_{j}^{*}-f_{j}^{-}\right)}=a_{i j}=G \frac{\left(c_{a_{i j}}, r_{a_{i j}}\right)}{A\left(a_{i j}\right)} \text {, }
\end{aligned}
$$

$f_{j}^{*}=\left\{\left(\max _{i} l_{i j}=G \frac{\left(c_{f_{j}^{*}}, r_{f_{j}^{*}}\right)}{A\left(f_{j}^{*}\right)} \mid j \in B\right)\right.$ or $\left.\left(\min _{i} l_{i j}=G \frac{\left(c_{f_{j}^{-}}, r_{f_{j}^{-}}\right)}{A\left(f_{j}^{-}\right)} \mid j \in C\right)\right\}$
$f_{j}^{-}=\left\{\min _{i} l_{i j}=G \frac{\left(c_{f_{j}^{-}}, r_{f_{j}^{-}}\right)}{A\left(f_{j}^{-}\right)} \mid j \in B\right)$ or $\left.\left(\max _{i} l_{i j}=G \frac{\left(c_{f_{j}^{*}}, r_{f_{j}^{*}}\right)}{A\left(f_{j}^{*}\right)} \mid j \in C\right)\right\}$,

where $B$ is associated with the benefit criterion, while $C$ is associated with the cost criterion and 


$$
\left.\begin{array}{l}
c_{a_{i j}}=\frac{\left(\left(c_{f_{j}^{*}}-c_{l_{i j}}\right) \times\left(c_{f_{j}^{*}}-c_{f_{j}^{-}}\right)\right)+\left(\left(r_{f_{j}^{*}}+r_{l_{i j}}\right) \times\left(r_{f_{j}^{*}}+r_{f_{j}^{-}}\right)\right)}{\left(c_{f_{j}^{*}}-c_{f_{j}^{-}}\right)^{2}-\left(r_{f_{j}^{*}}+r_{f_{j}^{-}}\right)^{2}} \\
r_{a_{i j}}=\frac{\left(\left(c_{f_{j}^{*}}-c_{l_{i j}}\right) \times\left(r_{f_{j}^{*}}+r_{f_{j}^{-}}\right)\right)+\left(\left(c_{f_{j}^{*}}-c_{f_{j}^{-}}\right) \times\left(r_{f_{j}^{*}}+r_{l_{i j}}\right)\right)}{\left(c_{f_{j}^{*}}-c_{f_{j}^{-}}\right)^{2}-\left(r_{f_{j}^{*}}+r_{f_{j}^{-}}\right)^{2}} \\
A\left(a_{i j}\right)=\frac{\left(\left(c_{f_{j}^{*}}-c_{l_{i j}}\right) \times\left(A\left(f_{j}^{*}\right)+A\left(f_{j}^{-}\right)\right)\right)+\left(\left(c_{f_{j}^{*}}-c_{f_{j}^{-}}\right) \times\left(A\left(f_{j}^{*}\right)+A\left(l_{i j}\right)\right)\right)}{\left(c_{f_{j}^{*}}-c_{f_{j}}\right)^{2}-\left(r_{f_{j}^{*}}+r_{f_{j}^{-}}\right)^{2}}
\end{array}\right\},
$$

$\therefore w_{j} \times \frac{\left(f_{j}^{*}-l_{i j}\right)}{\left(f_{j}^{*}-f_{j}^{-}\right)}=G \frac{\left(c_{w_{j}}, r_{w_{j}}\right)}{A\left(w_{j}\right)} \times G \frac{\left(c_{a_{i j}}, r_{a_{i j}}\right)}{A\left(a_{i j}\right)}=G \frac{\left(c_{\hat{a}_{i j}}, r_{\hat{a}_{i j}}\right)}{A\left(\hat{a}_{i j}\right)}$,

$i=1,2, \ldots, m ; j=1,2, \ldots, n$

where

$$
\left\{\begin{array}{l}
c_{\hat{a}_{i j}}=c_{w_{j}} c_{a_{i j}}+r_{w_{j}} r_{a_{i j}} \\
r_{\hat{a}_{i j}}=c_{w_{j}} r_{a_{i j}}+c_{a_{i j}} r_{w_{j}} \\
A\left(\hat{a}_{i j}\right)=c_{w_{j}} A\left(a_{i j}\right)+c_{a_{i j}} A\left(w_{j}\right)
\end{array} .\right.
$$
$\sum_{j \in C}\left[w_{j}\left(l_{i j}-f_{j}^{*}\right) /\left(f_{j}^{-}-f_{j}^{*}\right)\right]$ is done by interchanging the $l_{i j}$ and $f_{j}^{*}$ in $\left(f_{j}^{*}-l_{i j}\right)$ and $f_{j}^{*}$ and $f_{j}^{-}$in $\left(f_{j}^{*}-f_{j}^{-}\right)$of Eqs. (36-37).

$$
\therefore \frac{\left(l_{i j}-f_{j}^{*}\right)}{\left(f_{j}^{-}-f_{j}^{*}\right)}=b_{i j}=G \frac{\left(c_{b_{i j}}, r_{b_{i j}}\right)}{A\left(b_{i j}\right)} \text {. }
$$

Where $c_{b_{i j}}, \quad r_{b_{i j}}$, and $A\left(b_{i j}\right)$ are calculated by interchanging the position of $c_{f_{j}^{*}}$ and $c_{l_{i j}}$ in $\left(c_{f_{j}^{*}}-c_{l_{i j}}\right)$ and $c_{f_{j}^{*}}$ and $c_{f_{j}^{-}}$in $\left(c_{f_{j}^{*}}-c_{f_{j}^{-}}\right)$, respectively, in Eq. (39):

$$
\begin{aligned}
& \therefore\left(w_{j} \times \frac{\left(l_{i j}-f_{j}^{*}\right)}{\left(f_{j}^{-}-f_{j}^{*}\right)}\right)=\left(G \frac{\left(c_{w_{j}}, r_{w_{j}}\right)}{A\left(w_{j}\right)} \times G \frac{\left(c_{b_{i j}}, r_{b_{i j}}\right)}{A\left(b_{i j}\right)}\right) \\
& =G \frac{\left(c_{\hat{b}_{i j}}, r_{\hat{b}_{i j}}\right)}{A\left(\hat{b}_{i j}\right)},
\end{aligned}
$$

where

$$
\left\{\begin{array}{l}
c_{\hat{b}_{i j}}=c_{w_{j}} c_{b_{i j}}+r_{w_{j}} r_{b_{i j}} \\
r_{\hat{b}_{i j}}=c_{w_{j}} r_{b_{i j}}+c_{b_{i j}} r_{w_{j}} \\
A\left(\hat{b}_{i j}\right)=c_{w_{j}} A\left(b_{i j}\right)+c_{b_{i j}} A\left(w_{j}\right)
\end{array},\right.
$$

$$
\therefore S_{i}=\left\{\begin{array}{l}
=\sum_{j \in B}\left[w_{j}\left(f_{j}^{*}-l_{i j}\right) /\left(f_{j}^{*}-f_{j}^{-}\right)\right]+\sum_{j \in C}\left[w_{j}\left(l_{i j}-f_{j}^{*}\right) /\left(f_{j}^{-}-f_{j}^{*}\right)\right] \\
=\sum_{j \in B} G \frac{\left(c_{\hat{a}_{i j}}, r_{\hat{a}_{i j}}\right)}{A\left(\hat{a}_{i j}\right)}+\sum_{j \in C} G \frac{\left(c_{\hat{b}_{i j}}, r_{\hat{b}_{i j}}\right)}{A\left(\hat{b}_{i j}\right)} \\
=G \frac{\left(c_{\tilde{a}_{i}}, r_{\tilde{a}_{i}}\right)}{A\left(\tilde{a}_{i}\right)}+G \frac{\left(c_{\tilde{b}_{i}}, r_{\tilde{b}_{i}}\right)}{A\left(\tilde{b}_{i}\right)} \\
=G \frac{\left(c_{\bar{a}_{i}}, r_{\bar{a}_{i}}\right)}{A\left(\bar{a}_{i}\right)},
\end{array}\right.
$$

where

$$
\left\{\begin{array}{l}
\text { For Benefit criterion }(j \in B) \\
c_{\tilde{a}_{i}}=\sum_{j} c_{\hat{a}_{i j}}, \quad r_{\tilde{a}_{i}}=\sum_{j} r_{\hat{a}_{i j}}, A\left(\tilde{a}_{i}\right)=\sum_{j} A\left(\hat{a}_{i j}\right) \\
\text { For Cost } \operatorname{criterion}(j \in C) \\
c_{\tilde{b}_{i}}=\sum_{j} c_{\hat{b}_{i j}}, \quad r_{\tilde{b}_{i}}=\sum_{j} r_{\hat{b}_{i j}}, A\left(\tilde{b}_{i}\right)=\sum_{j} A\left(\hat{b}_{i j}\right) \\
\text { and } \\
c_{\bar{a}_{i}}=\left(c_{\tilde{a}_{i}}+c_{\tilde{b}_{i}}\right), \quad r_{\bar{a}_{i}}=\left(r_{\tilde{a}_{i}}+r_{\tilde{b}_{i}}\right), A\left(\bar{a}_{i}\right)=A\left(\tilde{a}_{i}\right)+A\left(\tilde{b}_{i}\right)
\end{array}\right.
$$




$$
\therefore R_{i}=\left\{\begin{array}{l}
=\left\{\begin{array}{l}
\max _{j \in B} w_{j}\left(f_{j}^{*}-l_{i j}\right) /\left(f_{j}^{*}-f_{j}^{-}\right) \\
\max _{j \in C} w_{j}\left(l_{i j}-f_{j}^{*}\right) /\left(f_{j}^{-}-f_{j}^{*}\right) \\
=\left\{\begin{array}{l}
\max _{j \in B} G \frac{\left(c_{\hat{a}_{i j}}, r_{\hat{a}_{i j}}\right)}{A\left(\hat{a}_{i j}\right)}=G \frac{\left(\max _{j \in B} c_{\hat{a}_{i j}}, \max _{j \in B} r_{\hat{a}_{i j}}\right)}{\max _{j \in B} A\left(\hat{a}_{i j}\right)}, \\
\max _{j \in C} G \frac{\left(c_{\hat{b}_{i j}}, r_{\hat{b}_{i j}}\right)}{A\left(\hat{b}_{i j}\right)}=G \frac{\left(\max _{j \in C} c_{\hat{b}_{i j}}, \max _{j \in C} r_{\hat{b}_{i j}}\right)}{\max _{j \in C} A\left(\hat{b}_{i j}\right)}
\end{array}\right. \\
=G \frac{\left(c_{\overline{\bar{a}}_{i}}, r_{\overline{\bar{a}}_{i}}\right)}{A\left(\overline{\bar{a}}_{i}\right)},
\end{array}\right.
\end{array}\right.
$$

where

$$
\left.\begin{array}{l}
c_{\overline{\bar{a}}_{i}}=\max \left(\max _{j \in B} c_{\hat{a}_{i j}}, \max _{j \in C} c_{\hat{b}_{i j}}\right) \\
r_{\overline{\bar{a}}_{i}}=\max \left(\max _{j \in B} r_{\hat{a}_{i j}}, \max _{j \in C} r_{\hat{b}_{i j}}\right) \\
A\left(\overline{\bar{a}}_{i}\right)=\max \left(\max _{j \in B} A\left(\hat{a}_{i j}\right), \max _{j \in C} A\left(\hat{b}_{i j}\right)\right)
\end{array}\right\} .
$$

Step 6 Compute the values $Q_{i}(i=1,2, \ldots, m)$ by these relations

$Q_{i}=v\left(S_{i}-S^{*}\right) /\left(S^{-}-S^{*}\right)+(1-v)\left(R_{i}-R^{*}\right) /\left(R^{-}-R^{*}\right)$,

where $v \approx 0.5$ is introduced as weight of the strategy of the 'maximum group utility' $v$.

Now, for the first part of Eq. (49), we have

$$
\left.\begin{array}{l}
S_{i}=G \frac{\left(c_{\bar{a}_{i}}, r_{\bar{a}_{i}}\right)}{A\left(\bar{a}_{i}\right)} \\
S^{*}=\min _{i} S_{i}=G \frac{\left(\min _{i} c_{\bar{a}_{i}}, \min _{i} r_{\bar{a}_{i}}\right)}{\min _{i} A\left(\bar{a}_{i}\right)}=G \frac{\left(c_{\bar{a}_{y}}, r_{\bar{a}_{y}}\right)}{A\left(\bar{a}_{y}\right)}, \quad(1 \leq y \leq m) \\
S^{-}=\max _{i} S_{i}=G \frac{\left(\max _{i} c_{\bar{a}_{i}}, \max _{i} r_{\bar{a}_{i}}\right)}{\max _{i} A\left(\bar{a}_{i}\right)}=G \frac{\left(c_{\bar{a}_{u}}, r_{\bar{a}_{u}}\right)}{A\left(\bar{a}_{u}\right)},(1 \leq u \leq m ; u>y)
\end{array}\right\},
$$

$$
\left.\begin{array}{l}
\left(S_{i}-S^{*}\right)=G \frac{\left(c_{\bar{a}_{i}}-c_{\bar{a}_{y}}, r_{\bar{a}_{i}}+r_{\bar{a}_{y}}\right)}{A\left(\bar{a}_{i}\right)+A\left(\bar{a}_{y}\right)} ; \\
\left(S^{-}-S^{*}\right)=G \frac{\left(c_{\bar{a}_{u}}-c_{\bar{a}_{y}}, r_{\bar{a}_{u}}+r_{\bar{a}_{y}}\right)}{A\left(\bar{a}_{u}\right)+A\left(\bar{a}_{y}\right)}
\end{array}\right\},
$$

$\therefore \frac{\left(S_{i}-S^{*}\right)}{\left(S^{-}-S^{*}\right)}=g_{i}=G \frac{\left(c_{g_{i}}, r_{g_{i}}\right)}{A\left(g_{i}\right)}$,

where

$$
\begin{aligned}
& c_{g_{i}}=\frac{\left(\left(c_{\bar{a}_{i}}-c_{\bar{a}_{y}}\right) \times\left(c_{\bar{a}_{u}}-c_{\bar{a}_{y}}\right)\right)+\left(\left(r_{\bar{a}_{i}}+r_{\bar{a}_{y}}\right) \times\left(r_{\bar{a}_{u}}+r_{\bar{a}_{y}}\right)\right)}{\left(c_{\bar{a}_{u}}-c_{\bar{a}_{y}}\right)^{2}-\left(r_{\bar{a}_{u}}+r_{\bar{a}_{y}}\right)^{2}} \\
& r_{g_{i}}=\frac{\left(\left(c_{\bar{a}_{i}}-c_{\bar{a}_{y}}\right) \times\left(r_{\bar{a}_{u}}+r_{\bar{a}_{y}}\right)\right)+\left(\left(c_{\bar{a}_{u}}-c_{\bar{a}_{y}}\right) \times\left(r_{\bar{a}_{i}}+r_{\bar{a}_{y}}\right)\right)}{\left(c_{\bar{a}_{u}}-c_{\bar{a}_{y}}\right)^{2}-\left(r_{\bar{a}_{u}}+r_{\bar{a}_{y}}\right)^{2}} \\
& A\left(g_{i}\right)=\frac{\left(\left(c_{\bar{a}_{i}}-c_{\bar{a}_{y}}\right) \times\left(A\left(\bar{a}_{u}\right)+A\left(\bar{a}_{y}\right)\right)\right)+\left(\left(c_{\bar{a}_{u}}-c_{\bar{a}_{y}}\right) \times\left(A\left(\bar{a}_{i}\right)+A\left(\bar{a}_{y}\right)\right)\right)}{\left(c_{\bar{a}_{u}}-c_{\bar{a}_{y}}\right)^{2}-\left(r_{\bar{a}_{u}}+r_{\bar{a}_{y}}\right)^{2}} \\
& \therefore v \frac{\left(S_{i}-S^{*}\right)}{\left(S^{-}-S^{*}\right)}=G \frac{\left(c_{v}, r_{v}\right)}{A(v)} \times G \frac{\left(c_{g_{i}}, r_{g_{i}}\right)}{A\left(g_{i}\right)} \\
& =G \frac{\left(c_{v} c_{g_{i}}+r_{v} r_{g_{i}}, c_{v} r_{g_{i}}+r_{v} c_{g_{i}}\right)}{c_{v} A\left(g_{i}\right)+c_{g_{i}} A(v)} \text {. }
\end{aligned}
$$

In addition, for the second part of Eq. (49), we have

$$
\left.\begin{array}{r}
R_{i}=G \frac{\left(c_{\overline{\bar{a}}_{i}}, r_{\overline{\bar{a}}_{i}}\right)}{A\left(\overline{\bar{a}}_{i}\right)} \\
R^{*}=\min _{i} R_{i}=G \frac{\left(\min _{i} c_{\overline{\bar{a}}_{i}}, \min _{i} r_{\overline{\bar{a}}_{i}}\right)}{\min _{i} A\left(\overline{\bar{a}}_{i}\right)}=G \frac{\left(c_{\overline{\bar{a}}_{r}}, r_{\overline{\bar{a}}_{r}}\right)}{A\left(\overline{\bar{a}}_{r}\right)}, \quad(1 \leq r \leq m)
\end{array}\right\} .
$$

Eqs. (50) and (51), we get,

$$
\begin{aligned}
& \frac{\left(R_{i}-R^{*}\right)}{\left(R^{-}-R^{*}\right)}=q_{i}=G \frac{\left(c_{q_{i}}, r_{q_{i}}\right)}{A\left(q_{i}\right)}, \\
& \therefore(1-v) \frac{\left(R_{i}-R^{*}\right)}{\left(R^{-}-R^{*}\right)}=G \frac{\left(c_{\hat{v}}, r_{\hat{v}}\right)}{A(\hat{v})} \times G \frac{\left(c_{q_{i}}, r_{q_{i}}\right)}{A\left(q_{i}\right)} \\
& \quad=G \frac{\left(c_{\hat{v}} c_{q_{i}}+r_{\hat{v}} r_{q_{i}}, c_{\hat{v}} r_{q_{i}}+r_{\hat{v}} c_{q_{i}}\right)}{c_{\hat{v}} A\left(q_{i}\right)+c_{q_{i}} A(\hat{v})},
\end{aligned}
$$


$Q_{i}=\left\{\begin{array}{l}=v\left(S_{i}-S^{*}\right) /\left(S^{-}-S^{*}\right)+(1-v)\left(R_{i}-R^{*}\right) /\left(R^{-}-R^{*}\right) \\ =G \frac{\left(c_{v} c_{g_{i}}+r_{v} r_{g_{i}}, c_{v} r_{g_{i}}+r_{v} c_{g_{i}}\right)}{c_{v} A\left(g_{i}\right)+c_{g_{i}} A(v)}+G \frac{\left(c_{\hat{v}} c_{q_{i}}+r_{\hat{v}} r_{q_{i}}, c_{\hat{v}} r_{q_{i}}+r_{\hat{v}} c_{q_{i}}\right)}{c_{\hat{v}} A\left(q_{i}\right)+c_{q_{i}} A(\hat{v})} \\ =G \frac{\left(\left(c_{v} c_{g_{i}}+r_{v} r_{g_{i}}\right)+\left(c_{\hat{v}} c_{q_{i}}+r_{\hat{v}} r_{q_{i}}\right)\right),\left(\left(c_{v} r_{g_{i}}+r_{v} c_{g_{i}}\right)+\left(c_{\hat{v}} r_{q_{i}}+r_{\hat{v}} c_{q_{i}}\right)\right)}{\left(c_{v} A\left(g_{i}\right)+c_{g_{i}} A(v)\right)+\left(c_{\hat{v}} A\left(q_{i}\right)+c_{q_{i}} A(\hat{v})\right)}, \\ =G \frac{\left(c_{t_{i}}, r_{t_{i}}\right)}{A\left(t_{i}\right)}\end{array}\right.$

where

$c_{t_{i}}=\left(c_{v} c_{g_{i}}+r_{v} r_{g_{i}}\right)+\left(c_{\hat{v}} c_{q_{i}}+r_{\hat{v}} r_{q_{i}}\right)$

$r_{t_{i}}=\left(c_{v} r_{g_{i}}+r_{v} c_{g_{i}}\right)+\left(c_{\hat{v}} r_{q_{i}}+r_{\hat{v}} c_{q_{i}}\right)$

$\left.A\left(t_{i}\right)=\left(c_{v} A\left(g_{i}\right)+c_{g_{i}} A(v)\right)+\left(c_{\hat{v}} A\left(q_{i}\right)+c_{q_{i}} A(\hat{v})\right)\right\}$

Applying $c_{v}=v, r_{v}=0, A(v)=0$ in Eq. (54) and $c_{\hat{v}}=(1-v), r_{\hat{v}}=0, A(\hat{v})=0$ in Eq. (57), and put in Eq. (58).

Step 7 Rank the alternatives $A_{i}(i=1,2, \ldots, m)$, sorting by the values $S_{i}(E q .(45)), R_{i}\left(E q\right.$. (47)) and $Q_{i}(E q$. (58)) in decreasing order. The results are three ranking lists that satisfies Steps 1 and 2 of Sect. 4.

Step 8 We propose as a compromise solution, the alternative $A_{\bar{p}}\left(=\min _{i} A_{i}\right) i=1,2, \ldots, m$ ranked best by the measure $Q$ (minimum) if the following two conditions (a)-(b) are satisfied:

(a) Acceptable advantage:

$$
\left.\begin{array}{l}
\left|Q\left(A_{\bar{p}+1}\right)-Q\left(A_{\bar{p}}\right)\right| \geq|D Q| \text { where } D Q=\frac{1}{(m-1)} \\
Q\left(A_{\bar{p}+1}\right)-Q\left(A_{\bar{p}}\right)=G \frac{\left(c_{t_{\bar{p}+1}}, r_{t_{\bar{p}+1}}\right)}{A\left(t_{\bar{p}+1}\right)}-G \frac{\left(c_{t_{\bar{p}}}, r_{t_{\bar{p}}}\right)}{A\left(t_{\bar{p}}\right)} \\
D Q=\frac{1}{(m-1)}=G \frac{(1,0)}{0} \div G \frac{(m-1,0)}{0}
\end{array}\right\},
$$

where $A_{\bar{p}+1}$ is the alternative with a second position on the ranking list by $Q$ and $m$ is the number of alternatives.

\section{(b) Acceptable stability in decision making:}

Alternative $A_{\bar{p}}$ must also be the best ranked by $S_{i}$ or/and $R_{i}$. This compromise solution is stable within a decision-making process, which could be strategy of "maximum group utility" (when $v>0.5$ is needed) or "by consensus" $(v \approx 0.5)$, or "with veto" $(v<0.5)$. Here, $v$ is the weight of the decision-making strategy of the majority of criteria (or "the maximum group utility").

If one of the conditions is not satisfied, then a set of compromise solutions with advantage rate is proposed, instead of only best alternative which consists of:

1. Alternative $A_{\bar{p}}$ and $A_{\bar{p}+1}$ if only condition (b) is not satisfied, or

2. Alternatives $A_{\bar{p}}, A_{\bar{p}+1}, \ldots, A_{M}$ if condition (a) is not satisfied, and $A_{M}$ is determined by the relation

$$
\left|Q\left(A_{M}\right)-Q\left(A_{\bar{p}}\right)\right|<|D Q|,
$$

for maximum $M$ (the positions of these alternatives are "in closeness").

The best alternative, ranked by $\mathrm{Q}$, is one with the minimum value of $\mathrm{Q}$. The main ranking result is the compromiseranking list of alternatives and the compromise solution with "advantage rate".

\section{Numerical illustration: green supplier chain risk management practices}

\subsection{Background scenario}

Considering the huge business opportunities of the plastic sector in India, the case of an instance of green supply chain management (GSCM) adopted from Mangla et al. (2015a, b), of a poly-plastic manufacturing company $\mathrm{XYZ}$ (name not disclosed) from northern India is singled out in this research.

- Green and sustainable supply chain management ensures that the industrial establishments are adopting clean and eco-friendly environmental practices in industrial areas, and are adopting reverse logistics thereby ensuring a low consumption of virgin resources, as well as stepping up the use of recyclable items (Govindan et al. 2014). 
- A growing environmental awareness amongst customers pushes the industrial houses for maintaining a green image, while strict governmental regulations alongside customers' demand force companies to ensure that their suppliers also enhance their environmental performance as they consider GSCM practices to be vital for organizations (Mangla et al. 2015a).

However, on the successful accomplishment of a GSCM, production and business activities are relatively difficult due to the involvement of different risks. In this research, an effort has been made to prioritize the risks and the responses to manage them while implementing the GSCM. The prioritization of responses to risks in GSCM is a multi-criteria decision-making (MCDM) problem involving various risk criteria and corresponding response alternatives that analyze AHP-VIKOR method in information granules. Granular-number-based AHP proposed by Alsawy and Hefny (2013b) is utilized in determining the important weights of the risks of the related supply chain, while the proposed extended granular-VIKOR method analyzes the appropriate responses to risks which are singled out to obtain their performance rating using a system of Granular numbers. The proposed method helps researchers and practitioners in understanding and prioritizing the appropriate risk responses when adopting GSCM.

In this study, the most frequently used green risk driver criteria are selected from Mangla et al. (2015a) and are identified from a prior procurement and green purchasing strategy assessment. The risk criteria chosen are Operational risks $\left(C_{1}\right)$, Supply risks $\left(C_{2}\right)$, Product recovery risks $\left(C_{3}\right)$, Financial risks $\left(C_{4}\right)$, and Demand risks $\left(C_{5}\right)$, the details of which is given in Table 4.

To manage these risks, four responses viz. Improved forecasting $\left(A_{1}\right)$, multiple supplier policy $\left(A_{2}\right)$, flexibility in operational level $\left(A_{3}\right)$, and well-designed reverse logistics system $\left(A_{4}\right)$ selected from Mangla et al. (2015b) are validated through an interactive discussion with the professionals of the decision-making team and is detailed in Table 5.

\subsection{Selection and ranking green supply chain risk criterion using granular AHP (G-AHP)}

In the following, we use the granular-AHP decision method to determine the weights $w_{j}(j=1,2, \ldots, 5)$ of the green supply risk criteria $C_{j}(j=1,2, \ldots, 5)$ by a group of decision makers $E_{p}(p=1,2,3)$, using a collection of multigranular linguistic information. The computational procedure is given in the following as per steps, as described in Sect. 6.2.

Step 1 For multiple experts $E_{p}(p=1,2,3)$, pairwise comparisons of the criteria $C_{j}(j=1,2, \ldots, 5)$ in the linguistic mode (Table 2) are first formed and then converted to multi-granular information's $(\mathrm{Z}, \tilde{a})^{p}$ using Table 1 and Eq. (10) of Sect. 5. The reciprocal decision matrices $\hat{R}^{p}(p=1,2,3)$ constructed as per Eq. (11) show the multigranular comparison along with its consistency ratio in Table 6.

Step 2 Using Eqs. $(12,13)$ of sub-sect. 6.2 and granular transformation functions defined in sub-sects. (3.1)-(3.5), the multi-granular reciprocal matrices $\hat{R}^{p}(p=1,2,3)$ are first transformed to its homogenous granular counterparts, and further aggregated using Eqs. (14-16) of Step 3 in subsect. 6.2. The details are shown in Table 7.

Step 3 Finally, the summation and normalization of the GSC risk-based criteria weights are computed using Eqs. (17-19) in Step 4 and Eqs. (20-24) in Step 5 of subsect. 6.2, respectively. The result is shown in Table 8. Each weight of the risk criteria $w_{j}(j=1,2, \ldots, 5)$ is expressed in the form of granular number is evaluated and ranked accordingly, using Eq. (2) in sub-sect. 2.2 and Steps 1-2 of Sect. 4.

Table 4 Defining GSCM specific risks with respective categories (Mangla et al. 2015a)

\begin{tabular}{ll}
\hline GSCM specific risks & Key factors in the mentioned risks \\
\hline Operational risks $\left(C_{1}\right)$ & $\begin{array}{l}\text { Interruption due to the failure of the industrial machine, flaws in designing of green process methodology, and lack } \\
\text { of knowledge of green operations among workforce lower GSCM performance } \\
\text { Procurement cost of green raw material, failure of any key supplier, and product quality issue can affect GSCM } \\
\text { efficiency at industrial perspective }\end{array}$ \\
Supply risks $\left(C_{2}\right)$ & $\begin{array}{l}\text { Risks relevant to reverse logistics network design, and gate keeping design (inspection and screening defective return } \\
\text { product) failure can disturb adoption of effective GSCM business practices }\end{array}$ \\
Financial risks $\left(C_{4}\right)$ & $\begin{array}{l}\text { Problems related to fund sourcing, Inflation and variations in currency exchange rate affect the financial concerns of } \\
\text { Green demand information distortion, Market dynamics, and key customer failure have a significant effect on effi- } \\
\text { cient GSCM adoption }\end{array}$ \\
\hline
\end{tabular}




\subsection{Evaluation of responses of risks in adoption of green initiative in GSC}

The next step is the prioritization of green supply risk responses with the proposed granular-based VIKOR procedure. In this stage, the experts $E_{p}(p=1,2,3)$ in the decision team are asked to evaluate and rank the four green risk response alternatives $A_{i}(i=1,2, \ldots, 4)$ against the riskbased criteria set $C_{j}(j=1,2, \ldots, 5)$, as described in Tables 4 and 5 , respectively. The stepwise computations are shown in the following.
Step 1 Similar to Step 1 in sub-sect. 8.2, the ratings of the alternatives $A_{i}(i=1,2, \ldots, 4)$ with respect to criteria $C_{j}(j=1,2, \ldots, 5)$ are also done in two phases, based on the decision of three different experts $E_{p}(p=1,2,3)$. Using Eqs. $(25,26)$ in step 1 of sub-sect. 7.2, the initial group decision-making matrices $D^{p}(p=1,2,3)$ are evaluated, first based on linguistic ratings (Tables 1,3) and, second, based on multi-granular linguistic data sets (Table 1). The details are shown in Table 9.

Step 2 Using Eqs. $(27,28)$ in Step 2 of sub-sect. 7.2, the heterogeneous linguistic decision matrices $D^{p}(p=1,2,3)$ are changed to homogeneous granular matrices

Table 5 Responses to risks in implementation of green supply chain (Mangla et al. 2015b)

\begin{tabular}{lc}
\hline Alternative responses & Description \\
\hline Improved forecasting $\left(A_{1}\right)$ & $\begin{array}{c}\text { Accurate forecast through improved forecasting method and techniques are significant to stabilize } \\
\text { the demand risk in GSCM in business } \\
\text { The policy of multiple suppliers helps in resolving the supplier risks and certainly improves the } \\
\text { economic-ecological gains in GSCM at industrial perspective }\end{array}$ \\
Multiple supplier policy $\left(A_{2}\right)$ & $\begin{array}{c}\text { The strategy of flexibility in design at process and operational level is significant in managing the } \\
\text { GSCM operations and will be useful in improving the overall performance }\end{array}$ \\
Flexibility in operational level $\left(A_{3}\right)$ & $\begin{array}{c}\text { Reverse logistics has been recognized as a significant operation in GSCM perspective in recovering } \\
\text { the resources via closing the forward supply loop }\end{array}$ \\
\hline
\end{tabular}

Table 6 Multi-granular decision-making matrices $\hat{R}^{p}$ for each expert $E_{p}(p=1,2, \ldots, k)$

\begin{tabular}{|c|c|c|}
\hline$\hat{R}^{1}=\left[\hat{t}_{i j}^{1}\right]_{5 \times 5}=$ & 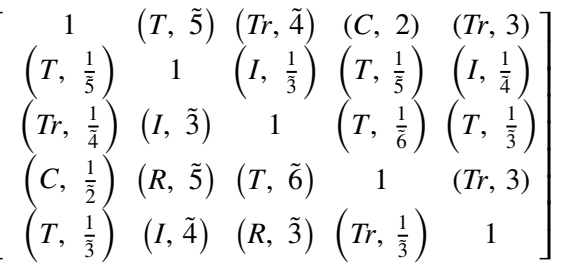 & $\mathrm{CR}=0.084<0.1$ \\
\hline$\hat{R}^{2}=\left[\hat{t}_{i j}^{2}\right]_{5 \times 5}=$ & {$\left[\begin{array}{ccccc}1 & \left(I, \frac{1}{\tilde{2}}\right) & \left(R, \frac{1}{\tilde{7}}\right) & \left(T, \frac{1}{\tilde{3}}\right) & (T r, 3) \\
(I, \tilde{3}) & 1 & \left(T, \frac{1}{\tilde{5}}\right) & \left(C, \frac{1}{\tilde{2}}\right) & (R, \tilde{3}) \\
(R, \tilde{7}) & (T, \tilde{5}) & 1 & (T, \tilde{\tilde{2}}) & (T r, \tilde{4}) \\
(T, \tilde{3}) & (C, \tilde{2}) & \left(T, \frac{1}{\tilde{2}}\right) & 1 & (C, \tilde{3}) \\
(\operatorname{Tr}, \tilde{3}) & \left(R, \frac{1}{\tilde{3}}\right) & \left(T r, \frac{1}{\tilde{4}}\right) & \left(C, \frac{1}{\tilde{3}}\right) & 1\end{array}\right]$} & $\mathrm{CR}=0.058<0.1$ \\
\hline$\hat{R}^{3}=\left[\hat{t}_{i j}^{3}\right]_{5 \times 5}=$ & 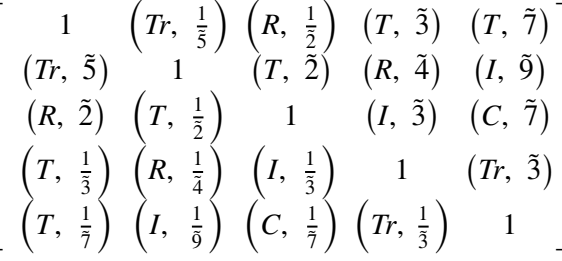 & $\mathrm{CR}=0.046<0.1$ \\
\hline
\end{tabular}

Table 7 Aggregated pairwise decision matrix

$$
\hat{H}=\left[\hat{g}_{i j}\right]_{5 \times 5}=\left[\begin{array}{llllll}
G \frac{(1.00,0.00)}{0.00} & G \frac{(1.97,0.48)}{0.60} & G \frac{(1.60,0.78)}{1.06} & G \frac{(1.79,0.38)}{0.36} & G \frac{(3.53,0.80)}{0.84} \\
G \frac{(2.40,1.01)}{1.68} & G \frac{(1.00,0.00)}{0.00} & G \frac{(0.86,0.39)}{0.43} & G \frac{(1.57,0.35)}{0.35} & G \frac{(4.09,0.69)}{1.04} \\
G \frac{(3.11,0.72)}{0.74} & G \frac{(2.89,0.78)}{1.11} & G \frac{(1.00,0.00)}{0.00} & G \frac{(1.72,0.68)}{1.01} & G \frac{(3.79,0.71)}{1.04} \\
G \frac{(1.29,0.38)}{1.13} & G \frac{(2.42,0.36)}{0.36} & G \frac{(2.35,0.49)}{0.53} & G \frac{(1.00,1.00)}{(3.00)} & G \frac{(3.00,1.33)}{.2 .00} \\
G \frac{(1.17,0.72)}{1.05} & G \frac{(1.50,0.38)}{0.72} & G \frac{(1.16,0.39)}{0.41} & G \frac{(0.51,0.27)}{0.35} & G \frac{(1.00,0.00)}{0.00}
\end{array}\right]
$$


Table 8 Overall priority of criteria

\begin{tabular}{lll}
\hline Criteria & Normalized G- Number & $\begin{array}{l}\text { Rank- } \\
\text { ing of } \\
\text { Criteria }\end{array}$ \\
\hline$C_{1}$ & $G \frac{0.2073,0.2020}{0.1814}$ & 4 \\
$C_{2}$ & $G \frac{0.2079,0.2022}{0.2211}$ & 3 \\
$C_{3}$ & $G \frac{0.2622,0.2392}{0.2472}$ & 1 \\
$C_{4}$ & $G \frac{0.2108,0.2115}{0.1904}$ & 2 \\
$C_{5}$ & $G \frac{0.1119,0.1451}{0.1599}$ & 5 \\
\hline
\end{tabular}

Table 9 Decision matrix $\left(D^{p}\right)$ as per heterogeneous data for experts $E_{p}(p=1,2,3)$

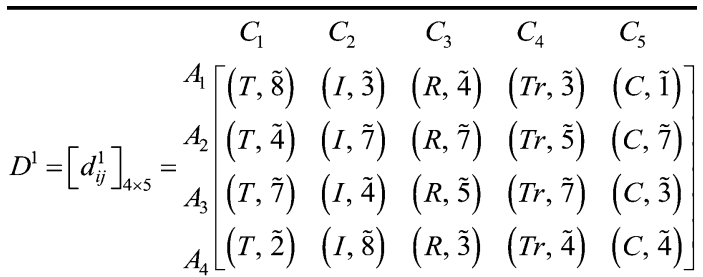

$$
\begin{aligned}
& \begin{array}{lllll}
C_{1} & C_{2} & C_{3} & C_{4} & C_{5}
\end{array}
\end{aligned}
$$

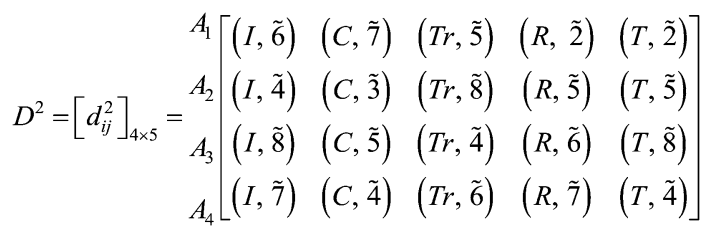

$$
\begin{aligned}
& \begin{array}{lllll}
C_{1} & C_{2} & C_{3} & C_{4} & C_{5}
\end{array}
\end{aligned}
$$

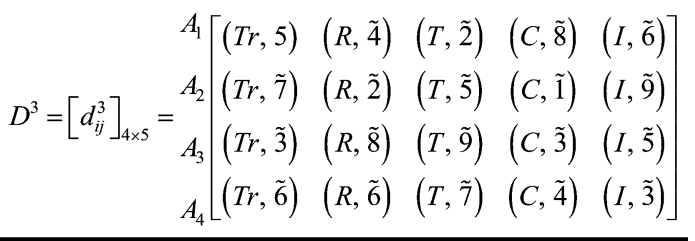

$J^{p}(p=1,2,3)$. Moreover, the corresponding aggregated granular decision matrix $\hat{L}(p=1,2,3)$ is formed using Eqs. (29-31) of step 3 in sub-sect. 7.2, and shown in Table 10.

Step 3 Applying Eqs. $(32,33)$ in Step 4 of sub-sect. 7.2 of the proposed methodology, the best value $f_{j}^{*}$ and the worst value $f_{j}^{-}$of all criteria functions $C_{j}(j=1,2, \ldots, 5)$ are determined and shown in Table 11. Here, we consider all
Table 11 Best and worst values of criteria $C_{j}(j=1,2, \ldots, 5)$

the criteria to be risky, so we take $j \in C$ (cost criteria) part in Eq. (32).

Step 4 For calculating values of $S_{i}(i=1,2, \ldots, 4)$ and $R_{i}(i=1,2, \ldots, 4)$, we take for the risk-based criteria $C_{j}(j=1,2, \ldots, 5), j \in C$ (cost criteria) in Eqs. $(34,35)$, respectively, for our case study.

Using Eqs. (42-46) and Eqs. (47, 48) in Step 5 of sub-sect. 7.2, the values of $S_{i}(i=1,2, \ldots, 4)$ and $R_{i}(i=1,2, \ldots, 4)$ are calculated, respectively, for all alternatives $A_{i}(i=1,2, \ldots, 4)$ and shown in Table 12 .

Step 5 Taking Eqs. (50-59) in step 6 of subsect. 7.2, the values of $Q_{i}(i=1,2, \ldots, 4)$ are calculated applying $c_{v}=0.5, r_{v}=0, A(v)=0$ in Eq. (54) and $c_{\hat{v}}=0.5, r_{\hat{v}}=0, A(\hat{v})=0$ in Eq. (57), and putting the same in Eq. (58). The result is shown in Table 12.

Step 6 Following step 7 of sub-sect. 7.2 and following the above results in Step 4-5 in sub-sect. 8.3, the alternatives are sorted by the values of $Q_{i}(i=1,2, \ldots, 5)$ in decreasing order. The results are three ranking lists along with compromise solution, as depicted in Table 12.

Step 7 Following as per Step 8 of sub-sect. 7.2, the alternative $\left(A_{1}\right)$ is the proposed compromise solution (as per ranking of $\left.Q_{i}\right)$ ranking best, followed by alternative $\left(A_{4}\right)$ by in the second position by $Q_{\text {min }}$, satisfying the two conditions (a) and (b).

(c.) Acceptable advantage

$$
\left|Q\left(A_{4}\right)-Q\left(A_{1}\right)\right| \geq|D Q| \text { is satisfied as }
$$

$$
\begin{aligned}
& \left|Q\left(A_{4}\right)-Q\left(A_{1}\right)\right|=\left|G \frac{(0.526,-1.338)}{0.348}-G \frac{(-0.336,-1.988)}{-1.192}\right| \\
& \quad=G \frac{(0.862,3.326)}{0.845} .
\end{aligned}
$$

\begin{tabular}{|c|c|c|c|c|c|}
\hline$\hat{L}=\left[l_{i j}\right]_{4 \times 5}=$ & $\begin{array}{l}G \frac{(6.333,1.333)}{2000} \\
G \frac{(5.000,1.333)}{2000} \\
G \frac{(6.000,1.333)}{20000} \\
G \frac{(5.000,1.333)}{2.000}\end{array}$ & $\begin{array}{l}G \frac{(4.667,0.667)}{1000} \\
G \frac{(4.000,0.667)}{1000} \\
G \frac{(5.667,0.667)}{10000} \\
G \frac{(6.000,0.667)}{1.000}\end{array}$ & $\begin{array}{l}G \frac{(3.667,1.333)}{1.667} \\
G \frac{(6.667,1.333)}{1667} \\
G \frac{(6.000,1.333)}{1.6 .7} \\
G \frac{(5.333,1.333)}{1.667}\end{array}$ & $\begin{array}{l}G \frac{(4.333,1.000)}{1.333} \\
G \frac{(3.667,1.000)}{1,333} \\
G \frac{(5.333,1.000)}{1333} \\
G \frac{(5.000,1.000)}{1.333}\end{array}$ & $\begin{array}{l}G \frac{(3.000,0.667)}{1000} \\
G \frac{(7.000,0.667)}{11000} \\
G \frac{(5.333,0.667)}{11.000} \\
G \frac{(3.667,0.667)}{1.000}\end{array}$ \\
\hline
\end{tabular}

Table 10 Aggregated G-number-based alternative decision matrix 
Table 12 Values of $S_{i}, R_{i}, Q_{i}$ for all alternatives $A_{i}(i=1,2, \ldots, 4)$

\begin{tabular}{lllllll}
\hline$\left(A_{i}\right)$ & $S_{i}$ & Rank & $R_{i}$ & Rank & $Q_{i}$ & Rank \\
\hline$A_{1}$ & $G \frac{(-0.249,-0.423)}{0.300}$ & 1 & $G \frac{(-0.026,-0.224)}{0.277}$ & 1 & $G \frac{(-0.336,-1.988)}{-1.192}$ & 1 \\
$A_{2}$ & $G \frac{(-0.090,-0.419)}{-0.682}$ & 2 & $G \frac{(0.210,0.398)}{0.143}$ & 4 & $G \frac{(0.576,-1.321)}{-0.407}$ & 3 \\
$A_{3}$ & $G \frac{(0.084,-0.233)}{-0.220}$ & 4 & $G \frac{(0.158,0.247)}{0.477}$ & 3 & $G \frac{(1.074,-0.846)}{1.613}$ & 4 \\
$A_{4}$ & $G \frac{(-0.045,-0.343)}{-0.395}$ & 3 & $G \frac{(0.105,0.227)}{0.410}$ & 2 & $G \frac{(0.526,-1.338)}{0.348}$ & 2 \\
\hline
\end{tabular}

Taking $m=4$ (no. of alternatives), we have

$|D Q|=\left|\frac{1}{(m-1)}\right|=\left|G \frac{(1,0)}{0} \div G \frac{(3,0)}{0}\right|=G \frac{(0.333,0)}{0}$.

(d.) Acceptable stability

Alternative $A_{1}$ also best ranked by $S_{i}$ and $R_{i}(i=1,2, \ldots, 4)$ (Table 12), thus condition (b) is also satisfied.

\section{Result discussion}

The proposed methodology is applied in prioritizing risk responses $A_{i}(i=1,2, \ldots, 4)$ to manage green supply chain risks $C_{j}(j=1,2, \ldots, 5)$ taking an Indian plastic manufacturering company XYZ as a case study. The result of the MCDM analysis (Table 12) suggested the following with respect to risk response alternatives:

- Improved forecasting $\left(A_{1}\right)$ and well-designed reverse logistics system $\left(A_{4}\right)$ better respond to green supply chain risk (GSC) in view of other two risk response strategies.

Besides the selection problem, the result in Table 8 also indicates the dominance of risks criteria, in order of importance.

- Product recovery risk $\left(C_{3}\right)$ has the maximum criteria weight followed by financial risk $\left(C_{4}\right)$ and supply risk $\left(C_{2}\right)$. The criteria, namely, operational risk $\left(C_{1}\right)$ and demand risk $\left(C_{5}\right)$, has a very low risk compared to others.

- In the present decade, the carbon footprint in the total set of greenhouse gas emissions (caused directly and indirectly by individuals and organization) is mainly due to the transportation and design patterns of the products, the reflection of which shown in the weight of criteria (Table 8).

To measure the influence of experts' to the final ranking of risk response to green supply chain risks, a sensitivity analysis is conducted through altering the values of $v$, which is shown in Table 13.

- The results show that the risk response alternative, namely, Improved forecasting $\left(A_{1}\right)$, has a maximum priority in all situations with ranks of other alternatives $A_{i}(i=2,3,4)$ changing, as per change in values of $v$ from $(v=0)$ to $(v=1)$ (Fig. 5).

- That is, the risk response alternatives multiple supplier policy $\left(A_{2}\right)$, flexibility in operational level $\left(A_{3}\right)$, and welldesigned reverse logistics system $\left(A_{4}\right)$ are dependent on the green supply risks preferences of decision makers.

The main attention is paid to check the stability and validity in ranking of the GSC risk-based criteria $C_{j}(j=1,2, \ldots, 5)$ and risk response alternatives $A_{i}(i=1,2, \ldots, 4)$, established by Granular-AHP and Granular-VIKOR in Tables 8 and 12, respectively.

- First, the ranking of criteria weights by the granular AHP (G-AHP) (Alsawy and Hefny 2013b) is compared with that done by existing MCDM methods viz. crisp AHP
Table 13 Sensitivity analysis of ranking in alternatives taking changing values of $v$

\begin{tabular}{llllllllllll}
\hline Alternative & $v=0$ & $v=0.1$ & $v=0.2$ & $v=0.3$ & $v=0.4$ & $v=0.5$ & $v=0.6$ & $v=0.7$ & $v=0.8$ & $v=0.9$ & $v=1.0$ \\
\hline$A_{1}$ & 1 & 1 & 1 & 1 & 1 & 1 & 1 & 1 & 1 & 1 & 1 \\
$A_{2}$ & 4 & 4 & 4 & 3 & 3 & 3 & 3 & 3 & 2 & 2 & 2 \\
$A_{3}$ & 3 & 3 & 3 & 4 & 4 & 4 & 4 & 4 & 4 & 4 & 4 \\
$A_{4}$ & 2 & 2 & 2 & 2 & 2 & 2 & 2 & 2 & 3 & 3 & 3 \\
\hline
\end{tabular}




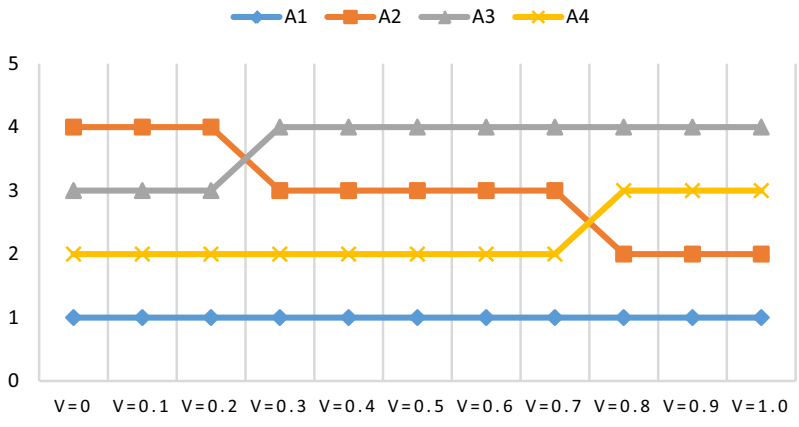

Fig. 5 Effect of changing of values of $v$ on ranking of alternatives

(Sokri et al. 2013), Grey AHP (Sahoo et al. 2016) and Rough AHP (Zhu et al. 2015a), detailed in Table 14.

- Based on the criteria weights in Table 14, the ranking of alternatives by proposed Granular-VIKOR method is compared with Crisp VIKOR (Sokri et al. 2013), Grey VIKOR (Celikbilek and Tuysuz 2016), and Rough VIKOR (Zhu et al. 2015b), as shown in Table 15.

- The same uncertain numbers are taken for ranking criteria weights and alternatives via. (G-AHP with G-VIKOR), (Crisp AHP with Crisp VIKOR), (Grey AHP with Grey VIKOR), and (Rough AHP with Rough VIKOR).

- Here, decision makers (DMs) take into account both group utility and individual regret and let parameter $v=0.5$. When the DMs are more concerned about group utility, we let parameter $0.5<v \leq 1$, and for individual regret, $0 \leq v \leq 1$ is used. Here, we take $v=0.5$.

- Based on the ranking results obtained in Tables 14 and 15, two comparative ranking analyses are performed in this section (Tables 16,17$)$ by calculating the Spearman's correlation coefficient $\left(r_{s}\right)$ relations (Ghorabaee et al. 2016) among the ranking order of variables.

- The value of $\left(r_{s}\right)$ is more when the ranking obtained from various methods are almost the same. Since the value of correlation coefficient $\left(r_{s}\right)$ obtained is equal or greater than 0.8 (threshold value), the relationship between variables is very strong, which confirms the validity and stability of the ranking results for both of G-AHP (in Table 14) and Grey VIKOR (in Table 15).

Thus, the proposed method can effectively reflect the decision makers' true perception and enhance the objectivity of decision-making for GSC risk responses. The number of criteria and alternatives in the proposed model are flexible, and firms can select them at will to suit their own decision-making circumstances and demands.

\section{Concluding remarks}

The information in decision-making problems is often found in diverse types of attributes, the values of which also happen to be imprecise. We are of the view that it is more appropriate to deal with such attributes in multiple formats. To this effect, we first developed an evaluation framework for assessing heterogeneous information in different domains and scales using experts' judgments. Next, different granular number transformation functions are applied to transform the value stored in several attributes into a
Table 14 Ranking results of G-AHP with other uncertainbased AHP methods

\begin{tabular}{lllll}
\hline Risk criteria & $\begin{array}{l}\text { G-AHP Alwasy and } \\
\text { Hefny (2013b) }\end{array}$ & $\begin{array}{l}\text { Crisp AHP Sokri } \\
\text { et al. (2013) }\end{array}$ & $\begin{array}{l}\text { Grey AHP Sahoo } \\
\text { et al. (2016) }\end{array}$ & $\begin{array}{l}\text { Rough AHP } \\
\text { Zhu et al. } \\
(2015 b)\end{array}$ \\
\hline Operational risks $\left(C_{1}\right)$ & 4 & 4 & 3 & 3 \\
Supply risks $\left(C_{2}\right)$ & 3 & 3 & 4 & 4 \\
Product recovery risk $\left(C_{2}\right)$ & 1 & 1 & 1 & 1 \\
Fina t al ncial risk $\left(C_{3}\right)$ & 2 & 2 & 2 & 2 \\
Demand risks $\left(C_{5}\right)$ & 5 & 3 & 5 & 5 \\
\hline
\end{tabular}

Table 15 Ranking results of G-VIKOR with other existing MCDM methods

\begin{tabular}{lllll}
\hline $\begin{array}{l}\text { Alternative risk } \\
\text { responses }\end{array}$ & $\begin{array}{l}\text { G-VIKOR* (Pro- } \\
\text { posed method) }\end{array}$ & $\begin{array}{l}\text { Crisp VIKOR Sokri } \\
\text { et al. (2013) }\end{array}$ & $\begin{array}{l}\text { Grey VIKOR Celikbilek } \\
\text { and Tuysuz (2016) }\end{array}$ & $\begin{array}{l}\text { Rough VIKOR } \\
\text { Zhu et al. } \\
(2015 \mathrm{~b})\end{array}$ \\
$A_{i}$ & $\mathrm{Q}_{\mathrm{i}}(v=0.5)$ & $\mathrm{Q}_{\mathrm{i}}(v=0.5)$ & $\mathrm{Q}_{\mathrm{i}}(v=0.5)$ & $\mathrm{Q}_{\mathrm{i}}(v=0.5)$ \\
\hline$A_{1}$ & 1 & 1 & 1 & 1 \\
$A_{2}$ & 3 & 3 & 3 & 2 \\
$A_{3}$ & 4 & 4 & 4 & 4 \\
$A_{4}$ & 2 & 2 & 2 & 3 \\
\hline
\end{tabular}


Table 16 Correlation coefficients between ranking results of G-AHP and other methods

\begin{tabular}{ll}
\hline $\begin{array}{l}\text { Comparison between MCDM methods for } \\
\text { GSC-based risk criteria weights }\end{array}$ & $\begin{array}{l}\text { Spearman's rank } \\
\text { correlation coeffi- } \\
\text { cient }\left(r_{s}\right)\end{array}$ \\
\hline G-AHP and Crisp AHP & 1 \\
G-VIKOR and Grey AHP & 0.9 \\
G-VIKOR and Rough AHP & 0.9 \\
\hline
\end{tabular}

$*$ Threshold value $=0.8$

Table 17 Correlation coefficients between the ranking results of G-VIKOR and other methods

\begin{tabular}{ll}
\hline $\begin{array}{l}\text { Comparison between MCDM methods for } \\
\text { ranking risk response alternatives }\end{array}$ & $\begin{array}{l}\text { Spearman's rank } \\
\text { correlation coeffi- } \\
\text { cient }\left(r_{s}\right)\end{array}$ \\
\hline G-VIKOR and Crisp VIKOR & 1 \\
G-VIKOR and Grey VIKOR & 1 \\
G-VIKOR and Rough VIKOR & 0.8 \\
\hline
\end{tabular}

$*$ Threshold value $=0.8$

common format. In this paper, we proposed a G-numberbased fusion method, combining the heterogeneous formats of subjective and numerical information, expressed on any scale and in any domain without any loss of information and under imprecise conditions.

In multi-criteria decision-making, we combine G-number with the AHP-VIKOR model in the heterogeneous formats of attribute values viz. crisp, fuzzy, interval and rough numbers, all the while assuming rational behaviour on part of the decision makers (DMs). The proposed model is effective and efficient for GSC risk prioritization and evaluation of the responses to risks. The main advantage of the proposed method is that it is capable of solving the MCDM problems in situations, where the criteria values, represented by the granular numbers, and the behaviour factor of the DMs are taken into account at the same time. Furthermore, the proposed method can adjust the parameter values according to the risk attitude of the DMs and the actual need, and this no doubt furthers the flexibility and reliability of decision processes. This green initiative in the supply chain due to clear logic and simple computational procedure gives the DM's yet another choice of methodology for solving the hybrid MADM problem.

In recent year's problems, GSCM can be used to explore the methods that will determine carbon footprint amongst the total set of greenhouse gas emissions and water-related risks involved with green supplier selection that are caused directly and indirectly by individuals, organizations, or events. To solve the uncertainty of a human subjective judgment, other concepts, such as grey set theory (Deng 1989), soft set theory (Molodtsov 1999), shadowed set theory (Pedrycz 1998), D number (Deng 2012), Z number (Zadeh 2011), and Hesitant set (Zhu et al. 2016), can be transformed accordingly and used as such, with the operations being comparable with existing results. In addition, incomplete information models can be further explored in which weights are attached to alternatives, experts, criteria, and so on that change dynamically over the time.

\section{References}

Alsawy A, Hefny H (2013a) On uncertain granular numbers. Int $\mathbf{J}$ Comput Appl 62(18):20-26. doi:10.5120/10181-5018

Alsawy A, Hefny H (2013b) Granular based analytical hierarchical process. 2013 IEEE International Conference on Granular Computing (GrC). doi:10.1109/GrC.2013.6740373

Alsawy A, Hefny H (2013c) Solving uncertain shortest path problem based on granular computing. 2013 IEEE International Conference on Computational Intelligence and Computing Research. doi:10.1109/ICCIC.2013.6724186

Bargiela A, Pedrycz W (2003) Granular computing-An Introduction. The Springer International Series in Engineering and Computer Science. Springer US 717(1): 1-472

Buckley J (1985) Fuzzy hierarchical analysis. Fuzzy Sets Syst 17(3):233-247. doi:10.1016/0165-0114(85)90090-9

Cabrerizo F, Herrera-Viedma E, Pedrycz W (2013) A method based on PSO and granular computing of linguistic information to solve group decision making problems defined in heterogeneous contexts. Eur J Oper Res 230(3):624-633. doi:10.1016/j. ejor.2013.04.046

Cabrerizo J, Ureña R, Pedrycz W, Herrera-Viedma E (2014) Building consensus in group decision making with an allocation of information granularity. Fuzzy Sets Syst 255:115-127. doi:10.1016/j. fss.2014.03.016

Celikbilek Y, Tuysuz F (2016) An integrated grey based multi-criteria decision-making approach for the evaluation of renewable energy sources. Energy 115:1246-1258. 10.1016/j.energy.2016.09.091

Chang D (1996) Applications of the extent analysis method on fuzzy AHP. Eur J Oper Res 95(3):649-655. doi:10.1016/0377-2217(95)00300-2

Chatterjee K, Kar S (2013a) An induced Fuzzy Rasch-VIKOR model for warehouse location evaluation under risky supply chain. In: Maji P, Ghosh A, Murty M, Ghosh K, Pal S (eds) Pattern recognition and machine intelligence (Proceedings of 5th International conference, PREMI 2013, Kolkata). Springer, New York, pp 714-719. doi:10.1007/978-3-642-45062-4

Chatterjee K, Kar M, Kar S (2013b) Strategic decisions using Intuitionistic fuzzy VIKOR method for Information System (IS) outsourcing. 2013 IEEE International Symposium of Computational and Business Intelligence (ISCBI). doi:10.1109/ISCBI.2013.33

Chen S, Chang C (2016) Fuzzy multiattribute decision making based on transformation techniques of intuitionistic fuzzy values and intuitionistic fuzzy geometric averaging operators. Inf Sci 352:133-149. doi:10.1016/j.ins.2016.02.049

Chen S, Tsai W (2016) Multiple attribute decision making based on novel interval-valued intuitionistic fuzzy geometric averaging operators. Inf Sci 367-368:1045-1065. doi:10.1016/j. ins.2016.07.018

Chen S, Cheng S, Tsai W (2016) Multiple attribute group decision making based on interval-valued intuitionistic fuzzy aggregation operators and transformation techniques of 
interval-valued intuitionistic fuzzy values. Inf Sci 367-368:418442. doi:10.1016/j.ins.2016.05.041

Deng J (1989) Introduction to Grey System Theory. J Grey Syst $1: 1-24$

Deng Y (2012) D numbers: theory and applications. J Inf Comput Sci 9(9):2421-2428. http://www.joics.com. Accessed 2 Sept 2016

Deng X, Hu Y, Deng Y, Mahadevan S (2014) Supplier selection using AHP methodology extended by D numbers. Expert Syst Appl 41:156-167. doi:10.1016/j.eswa.2013.07.018

Dubois D, Prade H (2016) Bridging gaps between several forms of granular computing. Granul Comput 1(2):115-126. doi:10.1007/ s41066-015-0008-8

Fan Z, Zhang X, Chen F, Liu Y (2013) Extended TODIM method for hybrid multiple attribute decision making. Knowl Based Syst 42:40-48. doi:10.1016/j.knosys.2012.12.014

Ghorabaee M, Zavadskas E, Turskis Z, Antucheviciene J (2016) A new combinative distance-based assessment (CODAS) method for multi-criteria decision-making, Economic computation and economic cybernetics studies and research. Acad Econ Stud 50(3):25-44. http://www.ecocyb.ase.ro. Accessed 2 Sept 2016

Govindan K, Kaliyan M, Kannan D, Haq A (2014) Barriers analysis for green supply chain management implementation in Indian industries using analytic hierarchy process. Int $\mathrm{J}$ Prod Econ 147(B):555-568. doi:10.1016/j.ijpe.2013.08.018

Guo J, Zhang W (2008) Selection of suppliers based on rough set theory and VIKOR algorithm. International Symposium on Intelligent Information Technology Application Workshops. IITAW'08, IEEE, 2008, pp 49-52

Han X, Chen X (2014) A D-VIKOR method for medicine provider selection. 2014 IEEE Seventh international joint conference on computational sciences and optimization. pp 419-423

Herrera F, Martinez L (2000) An approach for combining linguistic and numerical information based on the 2-tuple fuzzy linguistic representation model in decision-making. Int $\mathrm{J}$ Uncertain Fuzziness Knowl Based Syst 8(5):539-562. doi:10.1142/ S0218488500000381

Liao H, Xu Z (2013) A VIKOR-based method for hesitant fuzzy multi-criteria decision making. Fuzzy Optim Decis Making 12:373-392. doi: $10.1007 / \mathrm{s} 10700-013-9162-0$

Liao H, Xu Zeshui, Zeng X (2015) Hesitant fuzzy linguistic VIKOR method and its application in qualitative multiple criteria decision making. IEEE Trans Fuzzy Syst 23(5):13431355. doi:10.1109/TFUZZ.2014.2360556

Livi L, Sadeghian A (2016) Granular computing, computational intelligence, and the analysis of non-geometric input spaces. Granul Comput 1(1):13-20. doi:10.1007/s41066-015-0003-0

Mangla S, Kumar P, Barua M (2015a) Risk analysis in green supply chain using fuzzy AHP approach: a case study. Resour Conserv Recycl 104(B):375-390. doi:10.1016/j.resconrec.2015.01.001

Mangla S, Kumar P, Barua M (2015b) Prioritizing the responses to manage risks in green supply chain: An Indian plastic manufacturer perspective. Sustain Prod Consum I:67-86. doi:10.1016/j.spc.2015.05.002

Martinez L, Liu J, Ruan D, Yang J (2007) Dealing with heterogeneous information in engineering evaluation processes. Inf Sci 177(7):1533-1542. doi:10.1016/j.ins.2006.07.005

Mohamad D, Rofai N (2015) On arithmetic operations on G-number. 2015 IEEE International conference on Fuzzy Systems (Fuzz-IEEE) pp 1-8. doi:10.1109/FUZZ-IEEE.2015.7337820

Molodtsov D (1999) Soft set theory-first results. Comput Math Appl 37(4-5):19-31. doi:10.1016/S0898-1221(99)00056-5

Opricovic S, Tzeng H (2004) Compromise solution by MCDM methods: a comparative analysis of VIKOR and TOPSIS. Eur J Oper Res 156:445-455. doi:10.1016/S0377-2217(03)00020-1
Opricovic S, Tzeng G (2007) Extended VIKOR method in comparison with outranking methods. Eur J Oper Res 178:514-529. doi:10.1016/j.ejor.2006.01.020

Pedrycz W (1998) Shadowed sets: representing and processing fuzzy sets. IEEE Trans Syst Man Cybern Part B (Cybernetics) 28(1):103-109. doi:10.1109/3477.658584

Pedrycz W (2005) Knowledge-based clustering: from data to information granules. Wiley, Hoboken, NJ

Pedrycz W, Chen S (2011) Granular computing and intelligent systems: design with information granules of higher order and higher type. Springer, Heidelberg

Pedrycz W, Chen S (2015a) Information granularity, big data, and computational intelligence. Springer, Heidelberg

Pedrycz W, Chen S (2015b) Granular computing and decision-making: interactive and iterative approaches. Springer, Heidelberg

Pedrycz W, Gomide F (2007) Fuzzy systems engineering: toward human-centric computing. Wiley, Hoboken, NJ

Pedrycz W, Song M (2011) Analytic hierarchy process (AHP) in group decision making and its optimization with an allocation of information granularity. IEEE Trans Fuzzy Syst 19(3):527539. doi:10.1109/TFUZZ.2011.2116029

Pedrycz W, Song M (2014) A granulation of linguistic information in AHP decision-making problems. Inf Fusion 17:93-101. doi:10.1016/j.inffus.2011.09.003

Peng D, Gao C, Zhai L (2013) Multi-criteria group decision making with heterogeneous information based on ideal points concept. Int J Comput Intell Syst 6(4):616-625. doi:10.1080/18756891 .2013 .802112

Qin J, Liu X, Pedrycz W (2015).An extended VIKOR method based on prospect theory for multiple attribute decision making under interval type-2 fuzzy environment. Knowl Based Syst 86(C):116-130. doi:10.1016/j.knosys.2015.05.025

Rostamzadeh R, Govindan K, Esmaeili A, Sabaghi M (2015) Application of fuzzy VIKOR for evaluation of green supply chain management practices. Ecol Indic 49:188-203. doi:10.1016/j. ecolind.2014.09.045

Saaty T (1980) The analytic hierarchy process. McGraw-Hill, New York

Sahoo S, Dhar A, Kar A (2016) Environmental vulnerability assessment using Grey Analytical Hierarchy Process based model. Environ Impact Assess Rev 56: 145-154. http://dx.doi. org/10.1016/j.eiar.2015.10.002. Accessed 2 Sept 2016

Sayadi M, Heydari M, Shahanaghi K (2009) Extension of VIKOR method for decision making problem with interval numbers. Appl Math Modell 33(5):2257-2262. doi:10.1016/j. apm.2008.06.002

Shemshadi A, Shirazi H, Toreihi M, Tarokh M (2011) A fuzzy VIKOR method for supplier selection based on entropy measure for objective weighting. Expert Syst Appl 38:1216012167. doi:10.1016/j.eswa.2011.03.027

Skowron A, Jankowski A, Dutta S (2016) Interactive granular computing. Granul Comput 1(1):95-113. doi:10.1007/ s41066-015-0002-1

Sokri H, Ashjari B, Saberi M (2013) An integrated AHP-VIKOR methodology for Facility Layout design. Ind Eng Manag Syst 12(4):389-405. doi:10.7232/iems.2013.12.4.389

Van Laarhoven P, Pedrycz W (1983) A fuzzy extension of Saaty's priority theory. Fuzzy Sets Syst 11(3):199-227. doi:10.1016/ S0165-0114(83)80082-7

$\mathrm{Xu} \mathrm{Z} \mathrm{(2014)} \mathrm{Intuitionistic} \mathrm{fuzzy} \mathrm{analytic} \mathrm{hierarchy} \mathrm{process.}$ IEEE Trans Fuzzy Syst 22(4):749-761. doi:10.1109/ TFUZZ.2013.2272585

Xu Z, Wang H (2016) Managing multi-granularity linguistic information in qualitative group decision making: an overview. Granul Comput 1(1):21-25. doi:10.1007/s41066-015-0006-x 
Yao, Y (2004) Granular Computing. Proceedings of the 4th Chinese National Conference on Rough Sets and Soft Computing, Computer Science (Ji Suan Ji Ke Xue) 31:1-5

Zadeh L (2011) A note on Z-numbers. Inf Sci 181(14):2923-2932. doi:10.1016/j.ins.2011.02.022

Zhu B, Xu Z, Zhang R, Hong M (2015a) Generalized analytic network process. Eur J Oper Res 244(1):277-288. doi:10.1016/j. ejor.2015.01.011
Zhu G, Hu J, Gu C, Peng Y (2015b) An integrated AHP and VIKOR for design concept evaluation based on rough number. Adv Eng Informatics 29(3):408-418. doi:10.1016/j.aei.2015.01.010

Zhu B, Xu Z, Zhang R, Hong M (2016) Hesitant analytic hierarchy process. Eur J Oper Res 250:602-614 doi:10.1016/j. ejor.2015.09.063 